\title{
Estimation of Elastic and Damping Characteristics of Viscoelastically Constrained Carbon Strands
}

\author{
Sumit Vasudeva \\ Thesis submitted to the Faculty of the \\ Virginia Polytechnic Institute and State University \\ in partial fulfillment of the requirements for the degree of \\ Master of Science \\ in \\ Aerospace Engineering \\ Rakesh K. Kapania (Chair) \\ Eugene M. Cliff \\ Robert L. West \\ December $8^{\text {th }}, 2005$ \\ Blacksburg, Virginia \\ Keywords: Composites, Viscoelasticity, Prony Series, Buckling, Finite Element Method, \\ Passive Damping, Space Structures \\ Copyright@(2005, Sumit Vasudeva
}




\title{
Estimation of Elastic and Damping Characteristics of Viscoelastically Constrained Carbon Strands
}

\author{
Sumit Vasudeva
}

\begin{abstract}
$\underline{\text { Abstract }}$
Traditional large space structure construction incorporates the use of light-weight tubular metal alloys which have good strength to weight and stiffness to weight ratio. Recently, however, space structure construction has shifted focus on materials that are ultra light-weight, have high strength, have low package volume and possess excellent damping characteristics. Substantial damping is required in space since there is no surrounding medium to provide damping. Such a construction uses composites in a fabric form that displays viscoelastic behavior. The viscoelastic behavior is attributed to energy dissipation because of the shear stresses between the various fibrous strands that are kept in place by constraining viscoelastic layers. This type of vibration control falls under the rubric of passive damping of structures and has been found to have certain advantages over active damping such as less complexity as it does not require sensors, actuators and power supply that are needed for active damping.

One such material consists of woven carbon strands constrained by layers of viscoelastic damping material. Dynamics and buckling behavior of a structure in the form of a tube made from this material with metallic end caps is modeled and analyzed using commercially available Finite Element Analysis code ABAQUS ${ }^{\circledR}$. The current analysis deals with the
\end{abstract}


non-pressurized tube since the structure can maintain the tubular configuration as well as support end caps on account of the stiffness provided by the composites. Since no simple analytical approaches are available to predict damping of these materials, experimental data was used to estimate the damping characteristics of the material. The mass of the end cap was also estimated from the experimental impulse response as exact mass of the end cap (that was rigidly fixed to the tube) was unknown. 


\section{Acknowledgments}

I would like to express my sincere gratitude to Dr. Rakesh K. Kapania and Dr. Eugene M. Cliff for their guidance, patience and support throughout this work, to Dr. Robert L. West for agreeing to be on my committee, to Dr. Dhaval Makhecha for discussions on ABAQUS ${ }^{\circledR}$, to Mr. Stephen Scarborough of ILC Dover for his prompt answers to my questions regarding the tube specimen and to my group-mates for providing a very supportive and friendly environment.

I also acknowledge the support from Dr. Daniel Inman, Director, Center for Intelligent Material Systems and Structures and his graduate student Pablo Tarazaga for providing the experimental data that formed the basis of damping characterization. This work was supported by DARPA/SPO, NASA LaRC and the National Institute of Aerospace under grant VT-03-1, 2535. 


\section{Contents}

1 Introduction 1

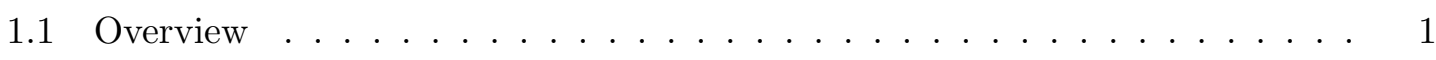

1.2 More on Passive Damping of Space Structures . . . . . . . . . . . . . . . . 4

1.3 Organization of Thesis $\ldots \ldots \ldots \ldots \ldots$

2 Problem Description $\quad 8$

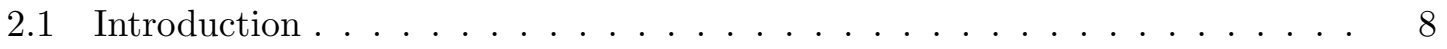

2.2 Tube Material Identification and Geometric Dimensions . . . . . . . . . . 9

3 Finite Element Formulation $\quad 13$

3.1 Introduction . . . . . . . . . . . . . . . . . . . . . . 13

3.2 Composite Material Modeling . . . . . . . . . . . . . . . . 15

3.3 Viscoelastic Material Modeling . . . . . . . . . . . . . . . . . . 16

4 Vibration and Buckling of Vertical Cantilever Tube 22

4.1 Introduction . . . . . . . . . . . . . . . . . . . 22

4.2 Equivalent Young's Modulus . . . . . . . . . . . . . . . . . . 23

4.3 Equivalent Shear Modulus . . . . . . . . . . . . . . . . . . . . 26

4.4 Transient Response . . . . . . . . . . . . . . . . . . . . . . 32 
4.5 Critical Buckling . . . . . . . . . . . . . . . 41

4.6 Natural Frequency and Buckling Analysis of a Ten Bay Truss . . . . . . . . 50

5 Conclusion and Future Work $\quad 56$

$\begin{array}{lr}\text { Appendices } & 64\end{array}$

$\begin{array}{ll}\text { A Half Power Method } & 64\end{array}$

$\begin{array}{ll}\text { B Linear Viscoelasticity } & 67\end{array}$

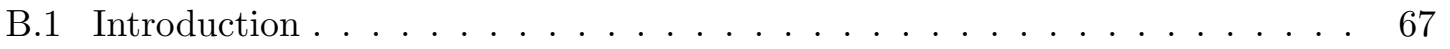

B.2 Constitutive Equations . . . . . . . . . . . . . . . . . . . 71

B.3 Mechanical Models . . . . . . . . . . . . . . . . . . . . . . . 71

$\begin{array}{ll}\text { C End Cap Dimensions } & 76\end{array}$

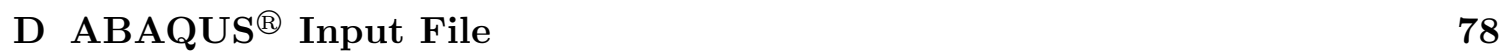

E ABAQUS ${ }^{\circledR}$ Input File For Truss $\quad 81$

$\begin{array}{llr}\text { F Nomenclature } & 83\end{array}$ 


\section{List of Figures}

2.1 The composite tube with an end cap placed in vertical clamped-free configuration. . . . . . . . . . . . . . . . . . . 10

2.2 The flange of the end cap at the boom base clamped to the heavy foundation. 11

2.3 The boom material. . . . . . . . . . . . . . . . . . . . . . 12

2.4 Flexible Piezoceramic Actuator placed on the boom. This actuator was however not studied here $[24] \ldots \ldots \ldots \ldots$. . . . . . . . . . . . 12

3.1 Element nomenclature as followed in ABAQUS ${ }^{\circledR}[25] . \ldots \ldots$. . . . . . 14

3.2 Layered composite assumption in ABAQUS ${ }^{\circledR}$ for the sparsely populated woven fabric. . . . . . . . . . . . . . . . . 16

3.3 Tensile creep properties for Kapton ${ }^{\circledR}$, Type HN Film [26] . . . . . . . . . . 18

3.4 Comparison plot of relaxation modulus from reference [27] and Prony series expansion found by ABAQUS ${ }^{\circledR}$ for PMMA. . . . . . . . . . . . . . . . 20 
3.5 Comparison plot of relaxation modulus from reference [26] and Prony series expansion of Kapton ${ }^{\circledR}$. The jagged plot of the Kapton ${ }^{\circledR}$ relaxation modulus at some places is due to the difficulty in manually selecting closely spaced points on a log-log plot while using Digitizeit ${ }^{\circledR}$. . . . . . . . . . . . . . . 2

4.1 Fast Fourier Transform of the velocity time data obtained for a point at the free end of the tube. The peak clearly shows the significance of the fundamental frequency for studying the impulse loading considered in this

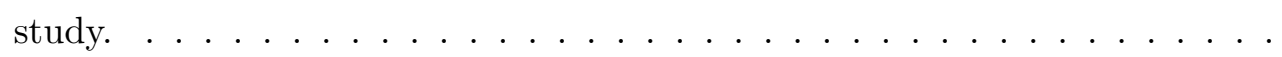

4.2 Comparison of mode shapes obtained for the tube modeled with shell elements as well as a $1 \mathrm{D}$ beam elements with tip masses. . . . . . . . . . . . 27

4.3 Comparison of the frequencies from the experimental Frequency Response Function and ABAQUS ${ }^{\circledR}$ for equivalent value of the Young's modulus. Assumption of equivalent Young's modulus for the tube based on fundamental natural frequency also gives the higher values of natural frequencies in close agreement to the ones experimentally found out. . . . . . . . . . 28

4.4 Consecutive torsion modes for an equivalent value of shear modulus of 6.8

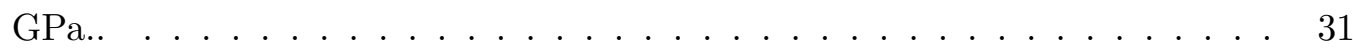

4.5 Impulse force function. . . . . . . . . . . . . . . . 35 
4.6 Velocity-time plot comparison of the experimental output and of a shell model in ABAQUS ${ }^{\circledR}$ with a tip mass of $0.207 \mathrm{Kg}$ and viscoelastically constrained carbon laminas with actual orthotropic elastic material properties. $\quad 36$

4.7 Velocity time plot comparison of the experimental output and ABAQUS ${ }^{\circledR}$ generated 1D beam with equivalent Young's modulus of $18.6 \mathrm{GPa}$. and experimentally determined Rayleigh parameters $\alpha=2.62 ; \beta=0.0000051$. . . 38

4.8 Velocity time plot comparison of the experimental output and ABAQUS ${ }^{\circledR}$ generated results for a 1D beam with reduced tip mass, estimated equivalent Young's modulus and estimated Rayleigh parameters. . . . . . . . . . . . . 39

4.9 Velocity time plot comparison of experimental output and ABAQUS ${ }^{\circledR}$ generated results for an elastic tube with reduced tip mass, estimated equivalent Young's modulus and estimated Rayleigh parameters. . . . . . . . . . . . . 40

4.10 Velocity Time Plot comparison of the experimental output and ABAQUS ${ }^{\circledR}$ modeled composite tube with reduced tip mass and material properties. $\quad$. 42

4.11 Velocity time plot comparison of the elastic tube with a value of Young's modulus of $13.5 \mathrm{GPa}$. and a composite tube with same geometric configuration having elastic modulus reduced by some percentage. . . . . . . . . . 43

4.12 Node Convergence study for the 1D beam. Estimated values of Young's modulus, tip mass and Rayleigh parameters are used for numerically generating the responses of two models having different number of elements. . . . 44 
4.13 Node Convergence study for the shell model. Estimated values of Young's modulus, end cap mass and Rayleigh parameters are used for numerically generating the responses of two models having different number of elements. 45

4.14 First five buckling modes for the isotropic tube with equivalent Young's modulus for lengths of $1.219 \mathrm{~m}$.(left) and $3 \mathrm{~m}$.(right). . . . . . . . . . . . 48

4.15 Comparison of the buckling mode shapes of an isotropic tube of estimated equivalent value of Young's modulus (left) and a composite tube with estimated values of the orthotropic material properties (right). . . . . . . . 49

4.16 Truss bending Modes. . . . . . . . . . . . . . . . . . . . 52

4.17 Truss torsion modes. . . . . . . . . . . . . . . . . . . . . . 53

4.18 Truss buckling modes. . . . . . . . . . . . . . . . . . . . 54

4.19 Ten bay truss composed of 1D beam elements in a clamped-free configuration. Tube end cap mass is modeled as lumped mass by loading the last element of each of the $1 \mathrm{D}$ beams in the truss with the estimated value of end cap mass. . . . . . . . . . . . . . . . . . . . . . . 55

5.1 A typical repeating element of a truss depicting diagonals, battens and

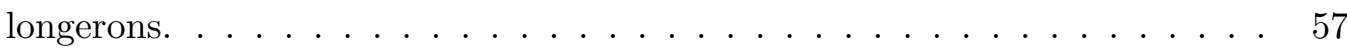

A.1 Frequency response curve depicting Half Power Points and corresponding frequencies for a peak corresponding to the beam bending mode. . . . . . . 66 
B.1 Strain response of Elastic, Viscous and Viscoelastic materials to identical stress loading. . . . . . . . . . . . . . . . . . . . . . . 69

B.2 Stress relaxation of viscoelastic material subjected to a constant strain. . . 70

B.3 Mechanical model analogues: a. Kelvin(Voigt) Model b. Maxwell Model c. Three Parameter Solid. . . . . . . . . . . . . . . . . . . . 73

B.4 Generalized Maxwell model. . . . . . . . . . . . . . . . . . . . . 74

B.5 Generalized Kelvin (Voigt) model. . . . . . . . . . . . . . . 75

C.1 Tube End Cap Dimensions. . . . . . . . . . . . . . . . . . . . 77 


\section{List of Tables}

2.1 Physical dimensions of the tube specimen. . . . . . . . . . . . . . . 11

3.1 Estimated values of the orthotropic elastic properties for the carbon to account for the voids in the composite material. The estimated values are $27.7 \%$ of the actual values. . . . . . . . . . . . . . . . 15

4.1 Comparison of the experimental, analytical and numerical values of the natural frequencies corresponding to first three tube bending modes obtained using the equivalent Young's modulus. . . . . . . . . . . . . . . . . 26

4.2 Comparison of the experimental and numerical values of the natural frequencies other than the bending modes obtained using the equivalent Young's modulus. ........................... 29

4.3 Comparison of the values of torsional frequencies obtained from analytical results with those from ABAQUS ${ }^{\circledR}$ for a tube with tip mass. . . . . . . . . 32

4.4 Comparison of the values of torsional frequencies obtained from analytical results with those from ABAQUS ${ }^{\circledR}$ for a tube without tip mass $\quad \ldots . .33$ 
4.5 Comparison of the experimental and numerical values of the natural frequencies corresponding to the first three tube bending modes obtained using the estimated equivalent Young's modulus and tip mass. . . . . . . . . . . . . . 37

4.6 Estimated values of the parameters. . . . . . . . . . . . . 41

4.7 Critical buckling loads without end mass. . . . . . . . . . . . . . . 47

4.8 Buckling load values for an isotropic tube and a composite one both having the same fundamental frequency. . . . . . . . . . . . . . . 47

4.9 First five frequencies corresponding to the truss bending and torsion modes. 51

4.10 Buckling load values. . . . . . . . . . . . . . . . . . . 55

C.1 Computed volume and mass for the end cap. . . . . . . . . . . . 76 


\section{Chapter 1}

\section{Introduction}

\section{$1.1 \quad$ Overview}

Space trusses are used for various types of space applications as they are generally composed of repeating elements that can be assembled easily, are lightweight and possess high stiffness [1]. Metallic tubings of circular cross sections find applications in the assembly of space trusses as battens, longerons and diagonals [2]. However, since these repeating elements have large longitudinal dimensions (of the order of 10 meters or more), they are often prone to large amplitude low frequency vibrations, which decreases the strength of the structure due to dynamic stresses, and the structure may thus fail due to fatigue. The cause of vibrations may be impulse/impact loadings. Such loadings are unavoidable because of routine phenomenon such as spacecraft dockings, repair/construction, and debris impact, etc. It is consequently desired to reduce the amplitude of the vibration of such structures as much as possible and that too in a shortest possible interval of time. Structural vibration damping can be achieved through active and/or passive means. 
Active means of structural vibration suppression is done by the optimum placement of actuators (such as piezoelectrics) and sensors. The effectiveness of such an approach in controlling the vibration depends on knowing the mode shapes of the structure for the optimal placement of actuators and sensors so as to control the structure in the best possible way. For structures such as trusses many complex mode shapes exist which might result in difficult set of actuator locations. The other means of vibration suppression is the so-called passive damping which requires the structural component material to have special properties such as viscoelasticity.

So far materials with very little inherent damping (such as metals) have been employed in the assembly of space structures. In passive damping, the inherent damping of the structure is augmented by using a high-damping material in the structure. Significant damping effects can also be achieved by incorporating viscoelastic materials in structural supports and pin connections $[3,4]$. Studies have been conducted on the passive vibration control of the response of truss type structures with tubular members $[5,6]$. The best way to achieve the desired objective of increased damping is to replace these materials with composites to achieve light weight and high strength and stiffness, viscoelastic materials or a combination of them, while still making the tube as thin as possible. The main source of mechanical damping in laminated composite materials is attributed to the inelastic nature of the matrix, relative slipping at the fiber/matrix interfaces, damping due to damage and viscoplastic damping $[7,8]$. Viscoelastic materials used alone in tubular members as the passive damping material would not provide the necessary stiffness for practical purposes 
as they have low values of elastic modulus. Also the dynamic behavior of such materials is temperature and frequency dependent [9].

The viscoelastic nature of composites and their ability to provide increased axial and bending stiffness could be a better way of realizing the desired objective of high damping and light weight. Consequently, composites are used in conjunction with viscoelastic materials. Applications of constrained layer damping treatments have been widely used as a source of damping in plates, beams and shells $[10,11]$. The damping capacity of composite laminates can be increased many times by incorporating viscoelastic damping layers between the laminae of the composites. In this hybrid approach, the dominant damping mechanism is the shear that is induced between the damping layer and the constraining layers [12]. In the present study the tubular structure is made of six layers of composite fibres laid out in different orientations in a fill and warp arrangement and constrained by a thin tape of viscoelastic material Kapton ${ }^{\circledR}$ (a Trademark of DuPont).

The structure under investigation has sufficient stiffness to support itself in vertical configuration and also support end caps. The structure is not internally pressurized. The dynamics and buckling of a pressurized tube, however, can be analyzed very easily in numerical simulation after subjecting the structure to internal pressure. Similar inflatable structures are finding increased applications in space structures such as solar sails, inflatable antennas, inflatable solar arrays, etc. Such structures have very low package volume, have increased design flexibility thereby enabling them to be made into a multitude of shapes, are extremely light and are generally deployed via inflation and become rigid once they are 
deployed and eliminate the dependence on inflation gas to maintain geometry [13]. The current research can be very easily extended to the analysis of inflatable structures.

\subsection{More on Passive Damping of Space Structures}

Many researchers have investigated the passive damping mechanisms of truss type space structures. Hagood and Crawley [14] conducted experiments to verify kinetic and strain energy damping enhancement schemes such as proof mass damping and resonant shunted piezoelectrics for lightly damped large space structures. They also presented a method for the analysis of damped structural systems in which the structural components are represented by impedance models and analysed in frequency domain [15]. Sankar and Deshpande [16] developed a series of analytical and numerical techniques for the analysis of large space structures subjected to constrained layer damping. They determined the natural frequencies, mode shapes and loss factors of a pin connected truss containing several damped members by three different methods namely truss finite element method, equivalent beam element, and scaled beam element method. Simonian et al [17] conducted experiments on a truss type cell with an optimal combination of damping mechanisms both in the form of viscoelastically damped mechanical joints as well as actuators and sensors.

Trudell et al [18] analyzed a combined approach of active and passive damping for a specific system. They found a beneficial synergism between active controls and passive damping. Rittweger et al [19] investigated passive damping devices for space structures based on the physical principles of coulomb friction, hydrodynamic and hydraulic concepts and viscoelas- 
tic bushings. Pamley et al [20] compared the effectiveness of different methods of applying passive damping such as extensional, constrained layer and viscosphere in-fill to hollow structures. Alsweify et al [21] experimentally investigated the free vibration of rectangular composite plates with an interlaminar viscoelastic damping layer in which the vibrational energy was found to dissipate via shear deformation. Natural frequencies, amplitudes and damping ratios were determined for the plates with and without damping layer. It was found that by adding a viscoelastic damping layer to the system the amplitude and the natural frequencies decreased. Johnson [22] discusses the techniques for passive damping of space structures in addition to the viscoelastic material usage. Edberg and Bicos [23] suggest a tailoring of composites to enhance the Poisson contraction and using a viscoelastic material placed in parallel to the load path to improve the damping characteristics. The objective of the present study is to estimate the elastic and damping characteristics of a material being proposed for large space structures. The material consists of woven carbon strands constrained by layers of viscoelastic material. A thin tube with an end cap (Aluminum) was tested in the Center for Intelligent Material Systems and Structures under impulse loads. Using a detailed ABAQUS ${ }^{\circledR}$ model and the experimental data, damping characteristics of this material were obtained. Since we were unable to remove the cap, the mass of the cap was also treated as an unknown in the identification process. Using identified mass of the cap, natural frequencies of the tube were studied. Two approaches were used - Beam Modeling and Shell Modeling. For first few modes, the beam model is found to yield results that are in good agreement with the shell model. The material 
properties identified in this study were also used to predict the buckling load of thin tubes made of carbon strands constrained by viscoelastic layers.

\subsection{Organization of Thesis}

The problem being investigated in this thesis is the numerical modeling of a physical system in the form of a tube in a vertical cantilever configuration with end caps. The experimentally measured tube dynamics show significant damping which is attributed to the passive damping caused by the use of composites and viscoelastic materials. The numerical model of the physical system is being sought so as to load it with improbable scenarios of loadings which might not be possible in a laboratory environment. But first, the damping and elastic characteristics of the material that went into the construction of the tubular structure are estimated using the experimental data. The dynamics of the numerical model under some assumptions is verified against one set of experimental results and is then extended to generate more results.

The thesis starts with some discussion on new developments in the area of space structure construction - the smart materials and inflatable structures replacing some of the conventional construction and describes some previous investigations on the topic. It is followed by the description of the problem, the experimental set up and as to why the current research is being done. Chapter 3 focuses on the discussion of the Finite Element formulation, the type of elements being used, the viscoelastic material modeling and the composite material modeling. Chapter 4 concentrates on comparison of the Finite Element 
results with the experimental results. The last chapter describes conclusions and suggestions for future work. Appendices on Half Power Method, Linear Viscoelasticity, some ABAQUS ${ }^{\circledR}$ input files and the Nomenclature followed throughout the thesis have been placed at the end. 


\section{Chapter 2}

\section{Problem Description}

\section{$2.1 \quad$ Introduction}

The physical structure is in the form of a thin cylindrical tube in a vertical cantilever configuration. Both ends of the tube have metal caps whose details are available and have been provided in the Appendix C. The flange of the metallic cap on one end is clamped rigidly to a heavy foundation as shown in Figure 2.2 which is further placed on damping pads to isolate the system from surrounding vibrations while the other end is free. The length of the tube considered in the numerical analysis is $1.2255 \mathrm{~m}$ which does not include the thickness of the clamped flange of the bottom end cap. The outer radius of the boom is $0.0508 \mathrm{~m}$.

The tube material is composed of composite fabrics constrained with a viscoelastic layer. There is no internal pressurization of the tube since the boom is stiff enough to carry its own weight and that of the end cap without buckling. It is also able to sustain its configuration during impact testing. 
The tube is given an impulse loading at the free end and its dynamic response is measured experimentally. The Frequency Response Function plots for the tube are also obtained. It is desired to make a Finite Element model of the structure and compare the numerical results with the experimental data. This is being investigated so that once a close match of the experimental and numerical simulations is achieved the model can be very easily subjected to multitude of dissimilar loadings such as a combination of axial loads, internal distributed loads and couples acting simultaneously. The distributed loading in the form of internal pressure will increase the stiffness of the tube and would have its affects on the dynamics as the frequencies will increase and the maximum displacements will decrease. This topic can form the next level of investigation.

\subsection{Tube Material Identification and Geometric Dimensions}

The exact geometric dimensions of the tube and the end caps were obtained from the manufacturer (ILC Dover) and are given in Table 2.1. A visual inspection of the material forming the boom reveals that the Carbon strips are arranged in $[-60 \backslash 0 \backslash 60]$ stacking sequence in a braided fill and warp arrangement spaced at a average distance of about 3

$\mathrm{mm}$ as shown in Figure 2.3. There are two plies of this fabric constrained in thin layers of Kapton $^{\circledR}$ on either side. The boom is made of the above described material.

In the present study only the impulse response of the structure is investigated for comparison with the numerical results. Although there are provisions in the experimental set up of applying piezoelectric actuation using piezoceramic fiber actuators such as Macro Fiber 


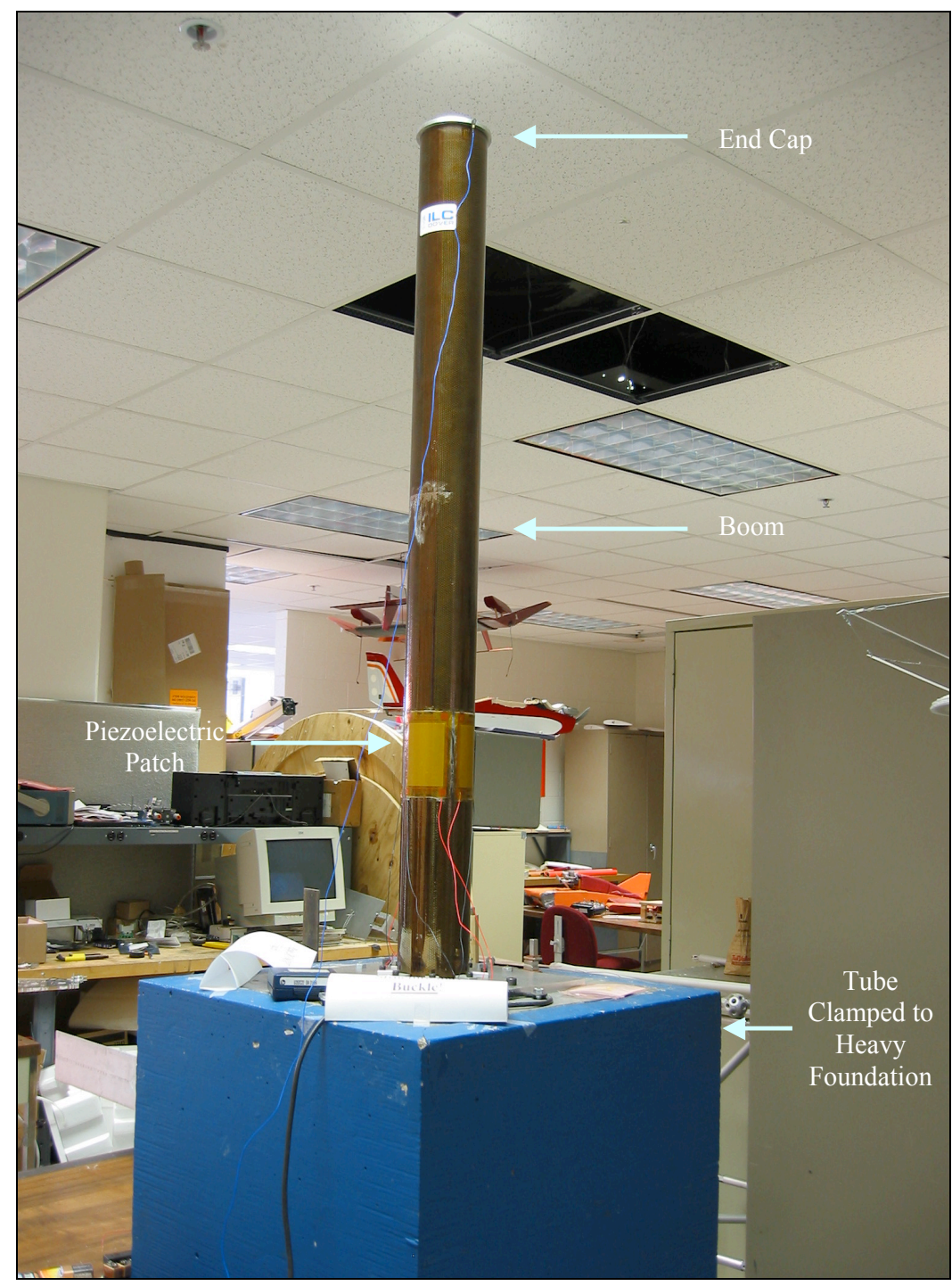

Figure 2.1: The composite tube with an end cap placed in vertical clamped-free configuration. 


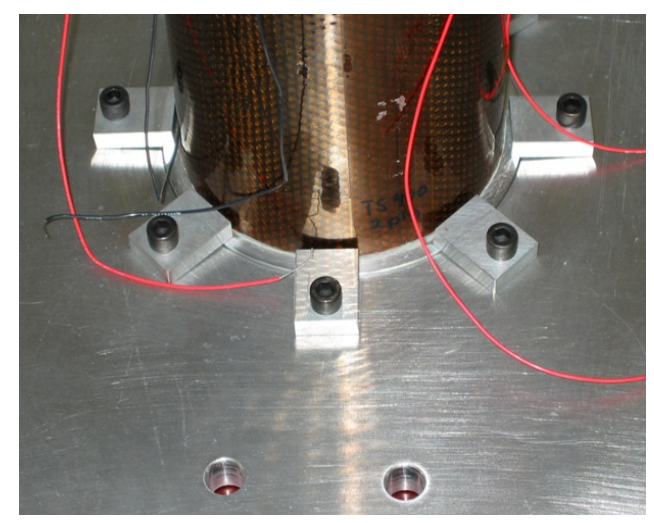

Figure 2.2: The flange of the end cap at the boom base clamped to the heavy foundation.

Table 2.1: Physical dimensions of the tube specimen.

\begin{tabular}{|c|c|}
\hline Parameter & Value \\
\hline Length & $1.2255 \mathrm{~m}$. \\
Tube Outer Radius & $0.05080 \mathrm{~m}$. \\
Tube Inner Radius & $0.05042 \mathrm{~m}$. \\
Manufacturer Specified Mass of End Cap & $0.207 \mathrm{Kg}$. \\
\hline
\end{tabular}

Composites [24] which can provide shear induced flexural vibrations to the tube. One such MFC is shown in Figure 2.4. The MFC was not used in the current study but may form the next level of investigation. Since the positioning of the piezoelectric actuator patch has important repercussions in the mode exciting, care needs to be exercised for its placement while the other research area could be the role of the patch as a damping inducer working in tandem with the material damping to curb the vibrations-the hybrid damping already discussed. 


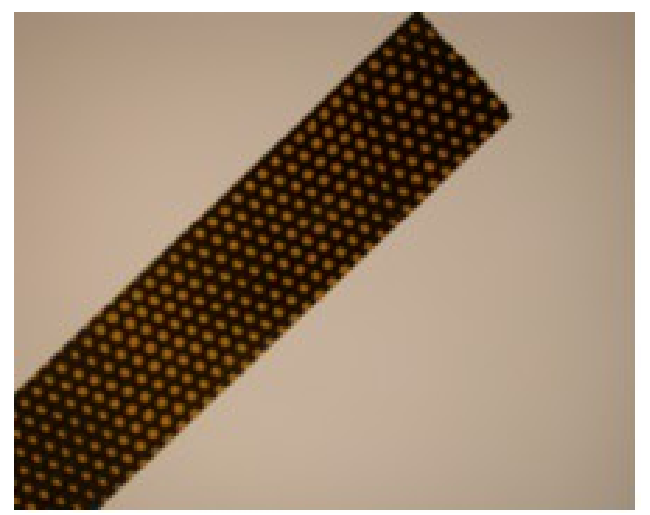

Figure 2.3: The boom material.

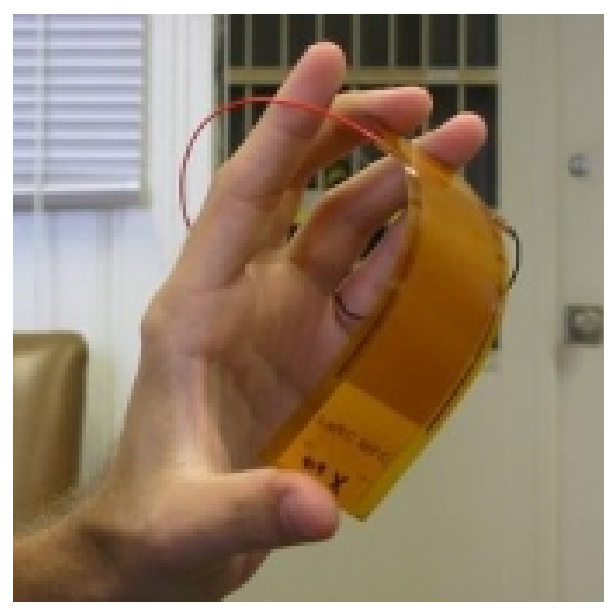

Figure 2.4: Flexible Piezoceramic Actuator placed on the boom. This actuator was however not studied here [24]. 


\section{Chapter 3}

\section{Finite Element Formulation}

\subsection{Introduction}

After getting to know the dimensions of the tube, the mass of the end caps and identifying the material and stacking sequence of the composite fibers [13], the model input file is first prepared in the PATRAN ${ }^{\circledR}$ pre-processor mainly for generating node connectivities and element definitions followed by its analysis in the ABAQUS ${ }^{\circledR}$ post processor.

The boom is modeled with shell elements S4R5 which are available in ABAQUS ${ }^{\circledR}$ for the analysis of thin shells. Thin shells are used in the analysis of structures where transverse shear flexibility is negligible and Kirchhoff constraint must be satisfied [25]. The free end tip mass is modeled using solid element C3D4, which is a 4 node linear tetrahedron element. More information on these elements can be found in the ABAQUS ${ }^{\circledR}$ manuals. The material of the shell is assumed to be made of laminas of the composites constrained with layers of viscoelastic material Kapton ${ }^{\circledR}$ on either side. 

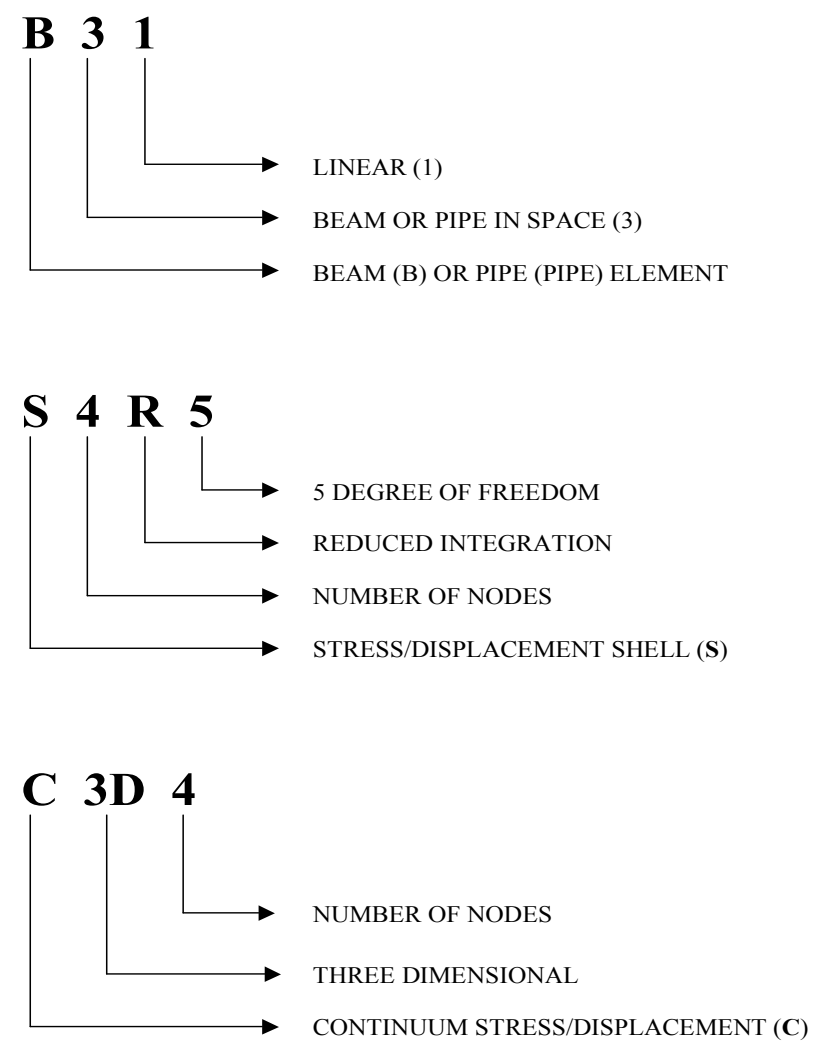

Figure 3.1: Element nomenclature as followed in ABAQUS ${ }^{\circledR}[25]$. 
Table 3.1: Estimated values of the orthotropic elastic properties for the carbon to account for the voids in the composite material. The estimated values are $27.7 \%$ of the actual values.

\begin{tabular}{|c|c|c|}
\hline Elastic Material Properties $\left(\mathrm{kN} / \mathrm{mm}^{2}\right)$ & Actual Values & Estimated Values \\
\hline $\mathrm{E}_{11}$ & 135 & 37.46 \\
$\mathrm{E}_{22}$ & 13 & 3.60 \\
$\mathrm{G}_{12} / \mathrm{G}_{13}$ & 6.4 & 1.77 \\
$\mathrm{G}_{23}$ & 4.3 & 1.19 \\
\hline
\end{tabular}

\subsection{Composite Material Modeling}

ABAQUS ${ }^{\circledR}$ can model the composite structures as laminas, that is layers of same or different materials placed over one another as is seen in most of the composite construction. But it does not have the provision for taking care of spaced material strips in both fill and warp direction with a moderate amount of resin content. To account for the spaced strips instead of a continuous sheet of lamina, it is assumed that the structure being investigated has laminas of carbon at same orientations as specified by the manufacturer (ILC Dover) but the nominal values of orthotropic elastic moduli in all directions are reduced by some percentage. The new values of the material properties arrived at (as given in Table 3.1) give the same value of the fundamental frequency as measured experimentally for the structure. In ABAQUS ${ }^{\circledR}$ a lamina is considered an orthotropic sheet in plane stress. Local coordinate system for the definition of material properties is specified for each layer. A shell section option is used which is defined by giving the layer thickness, material properties and orientation in which case ABAQUS ${ }^{\circledR}$ preintegrates the globally transformed plane stress- 

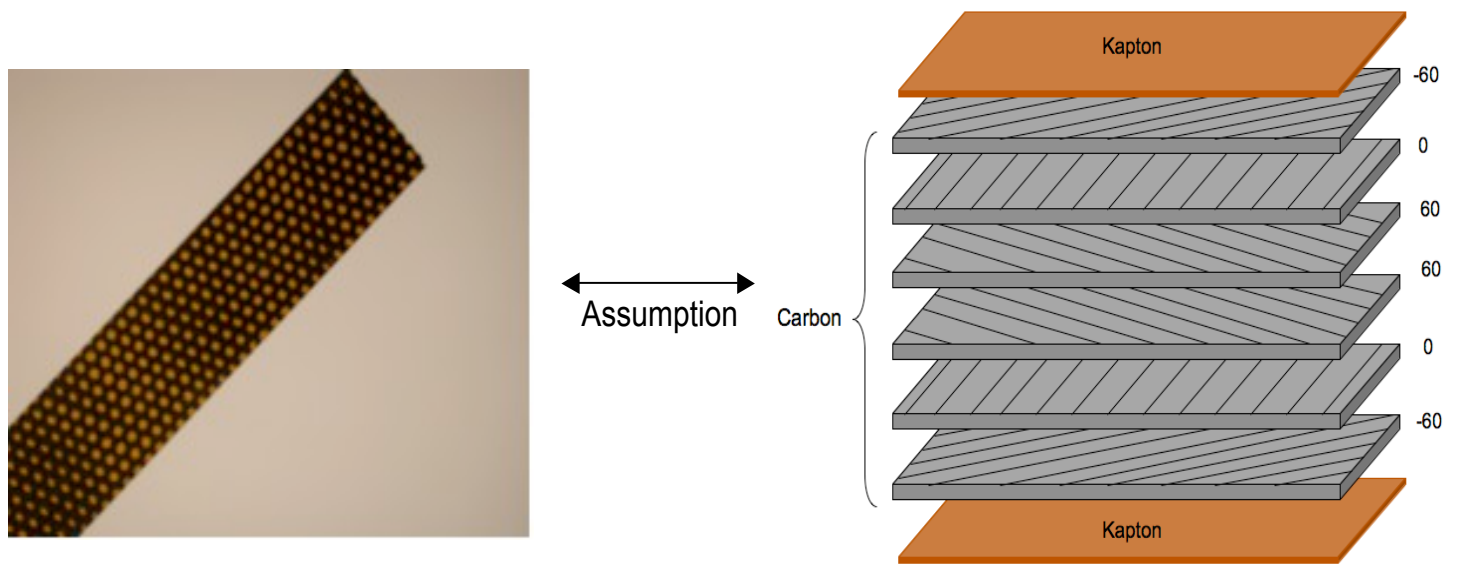

Figure 3.2: Layered composite assumption in ABAQUS ${ }^{\circledR}$ for the sparsely populated woven fabric.

reduced stiffnesses to obtain section stiffness properties directly in the form of matrices $[\mathrm{A}],[\mathrm{B}]$ and $[\mathrm{D}]$ which are used for deflection and frequency outputs [25].

\subsection{Viscoelastic Material Modeling}

The carbon fiber strands are restrained by thin layers of Kapton ${ }^{\circledR}$ on either side which is a viscoelastic material. ABAQUS ${ }^{\circledR}$ assumes that the viscoelastic material is defined by a Prony series expansion of the dimensionless relaxation modulus when the material is considered as a general Maxwell solid. The relaxation modulus is given by

$$
E(t)=E_{0}\left[1-\sum_{i=1}^{n} p_{i}\left(1-e^{-t / \tau_{i}}\right)\right]
$$

at time $t=0$

$$
E(0)=E_{0}
$$


and at time $t=\infty$

$$
E(\infty)=E_{0}\left[1-\sum p_{i}\right]
$$

Tensile creep properties for Kapton ${ }^{\circledR}$ are shown in Figure 3.3. The figure shows the variation of percent elongation of a sample of a $25 \mu \mathrm{m}$ thick type HN film of Kapton ${ }^{\circledR}$ with respect to time on a $\log -\log$ plot at different temperatures. The graph was obtained from the Kapton ${ }^{\circledR}$ website [26]. Variation of relaxation modulus with time for Kapton ${ }^{\circledR}$ at a particular temperature can be obtained easily if the numbers that went into the making of the plot in Figure 3.3 can be obtained. For obtaining the creep test results from Figure 3.3 a free trial version of Digitizeit ${ }^{\circledR}$ developed by Ingo Bormann of Bormisoft was used. It is a software which is used in extracting the data values from a graph i.e. digitizing a scanned graph into $(\mathrm{x}, \mathrm{y})$ data. Since the creep properties of Kapton ${ }^{\circledR}$ were not available in open literature it was decided to extract the values from such a graph available online.

A history dependent viscoelastic material model describes the isotropic rate-dependent material behavior and assumes that the shear and volumetric behaviors are independent in multiaxial stress states and can also be used in conjunction with the linear elastic behavior [25]. Time domain viscoelasticity is available in ABAQUS ${ }^{\circledR}$ for small strain applications where the rate-dependent elastic response can be defined with a linear elastic material model. Appendix B briefly describes the theory of linear viscoelasicity. ABAQUS ${ }^{\circledR}$ has a provision of providing the Prony Series parameters when the creep data is supplied to it.

The accuracy and correctness of the Prony parameters being obtained for Kapton ${ }^{\circledR}$ by 


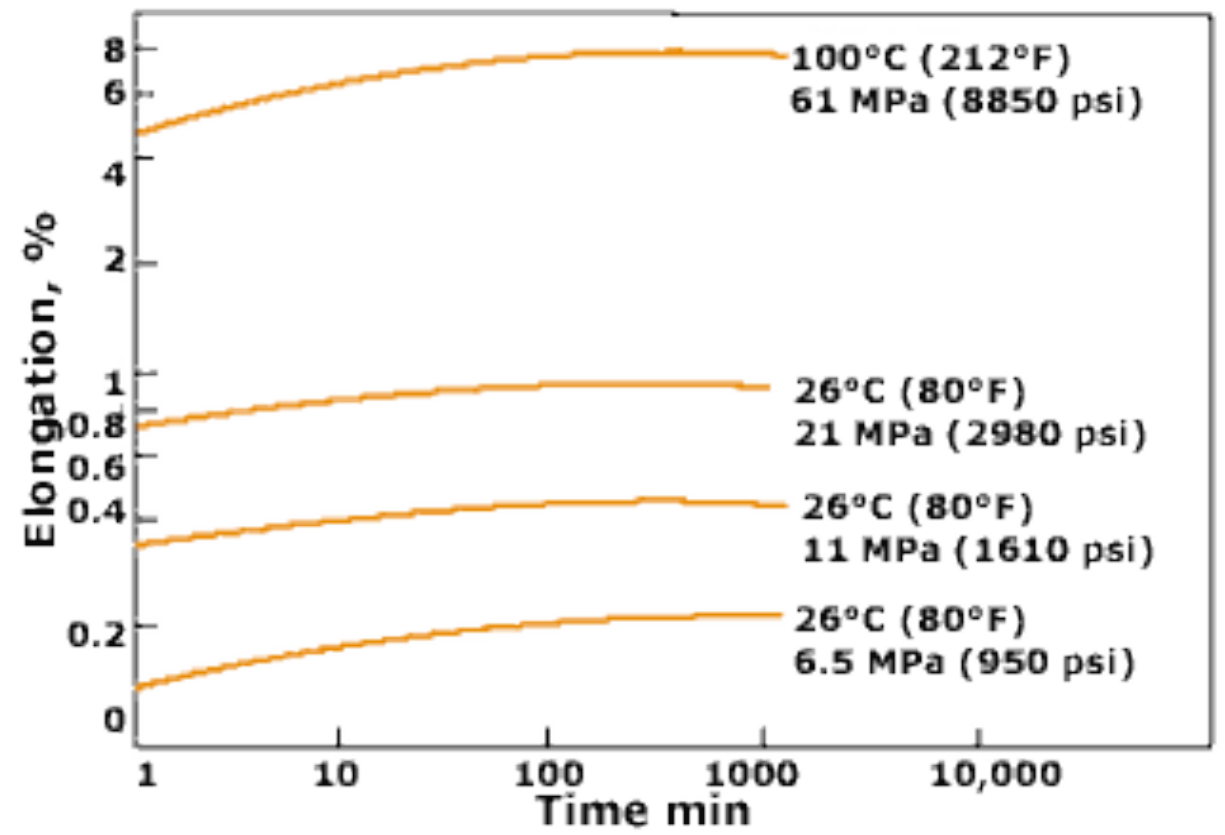

Figure 3.3: Tensile creep properties for Kapton ${ }^{\circledR}$, Type HN Film [26]. 
ABAQUS ${ }^{\circledR}$ was first checked by validating the input file used to do so, against a known material such as Poly Methyl Methacrylate (PMMA). For PMMA, Muki and Sternberg [27] fit the following relation to experimental data for the relaxation modulus.

$$
E(t)=10^{8.85}\left(0.0316+63(t+3.98)^{-1 / 2}-15.5\left(7.94(t+3.98)^{-3 / 2}-e^{-1.89 t}\right)\right)
$$

This equation gives the variation of relaxation modulus with time for PMMA for which the Prony Series parameters are obtained by ABAQUS ${ }^{\circledR}$. Using ABAQUS ${ }^{\circledR}$ the following three term Prony Series approximation is found for PMMA. The units of E and $t$ as used in the equation are shown in Figure 3.4.

$$
\frac{E(t)}{E(0)}=1-\left(0.439\left(1-e^{-t / 0.534}\right)+0.329\left(1-e^{-t / 27.25}\right)+0.1748\left(1-e^{-t / 247.7}\right)\right)
$$

The input file used to obtain the results for PMMA, which is checked for its correctness as depicted in Figure 3.4, is used for Kapton ${ }^{\circledR}$. For Kapton ${ }^{\circledR}$ the following three term Prony Series is found by feeding the creep data as obtained from Figure 3.3 to the input file. The units of $\mathrm{E}$ and $\mathrm{t}$ as used in the equation are shown in Figure 3.5.

$$
\frac{E(t)}{E(0)}=1-\left(0.4706\left(1-e^{-t / 0.3825}\right)+0.07348\left(1-e^{-t / 17.40}\right)+0.0369\left(1-e^{-t / 117.6}\right)\right)
$$

Figures 3.4 and 3.5 show the closeness of the experimental data and the Prony Series approximation as obtained by ABAQUS ${ }^{\circledR}$ for the different materials being studied. ABAQUS ${ }^{\circledR}$ finds the Prony series parameters by employing a built-in non linear least square curve fitting algorithm. 


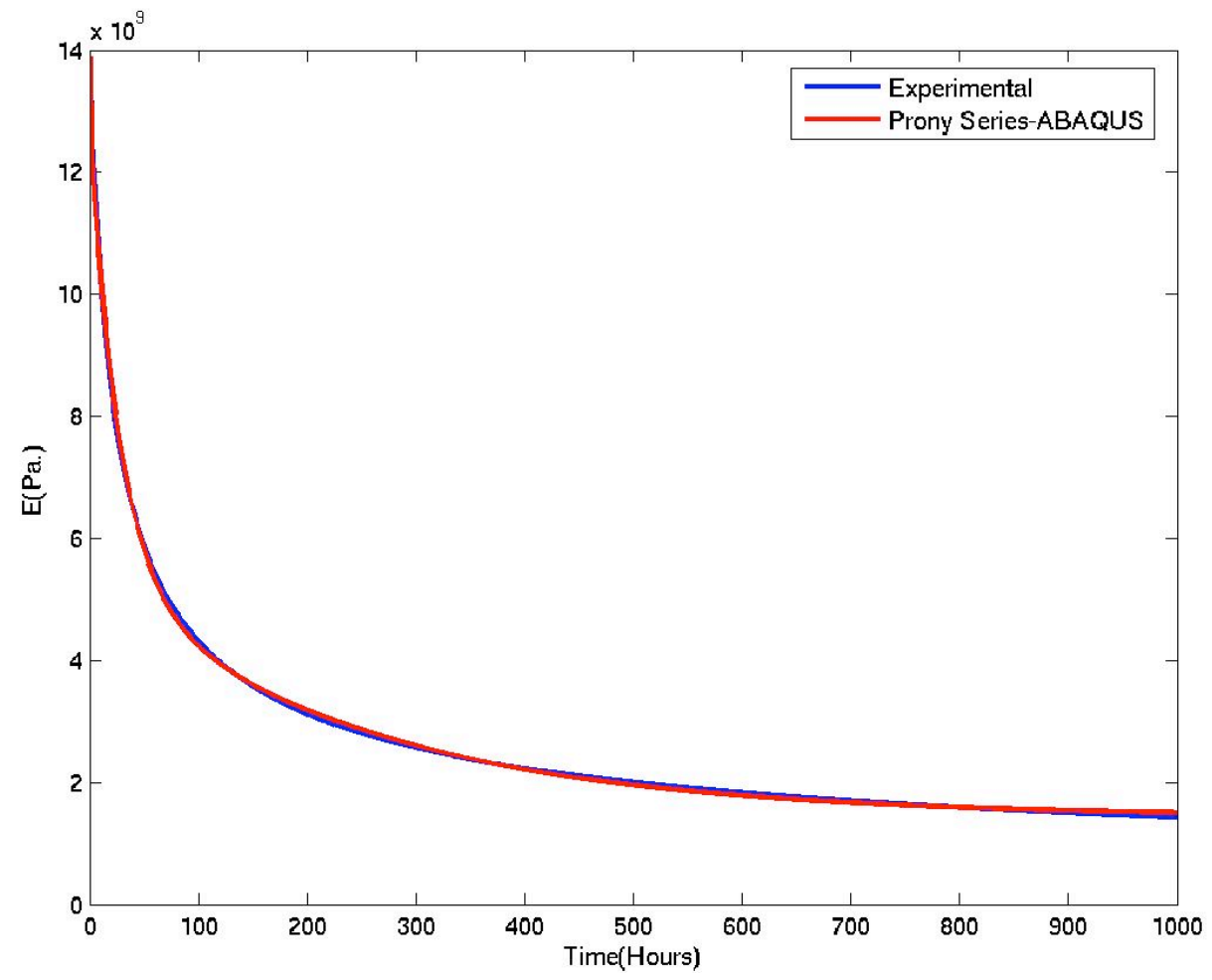

Figure 3.4: Comparison plot of relaxation modulus from reference [27] and Prony series expansion found by ABAQUS ${ }^{\circledR}$ for PMMA. 


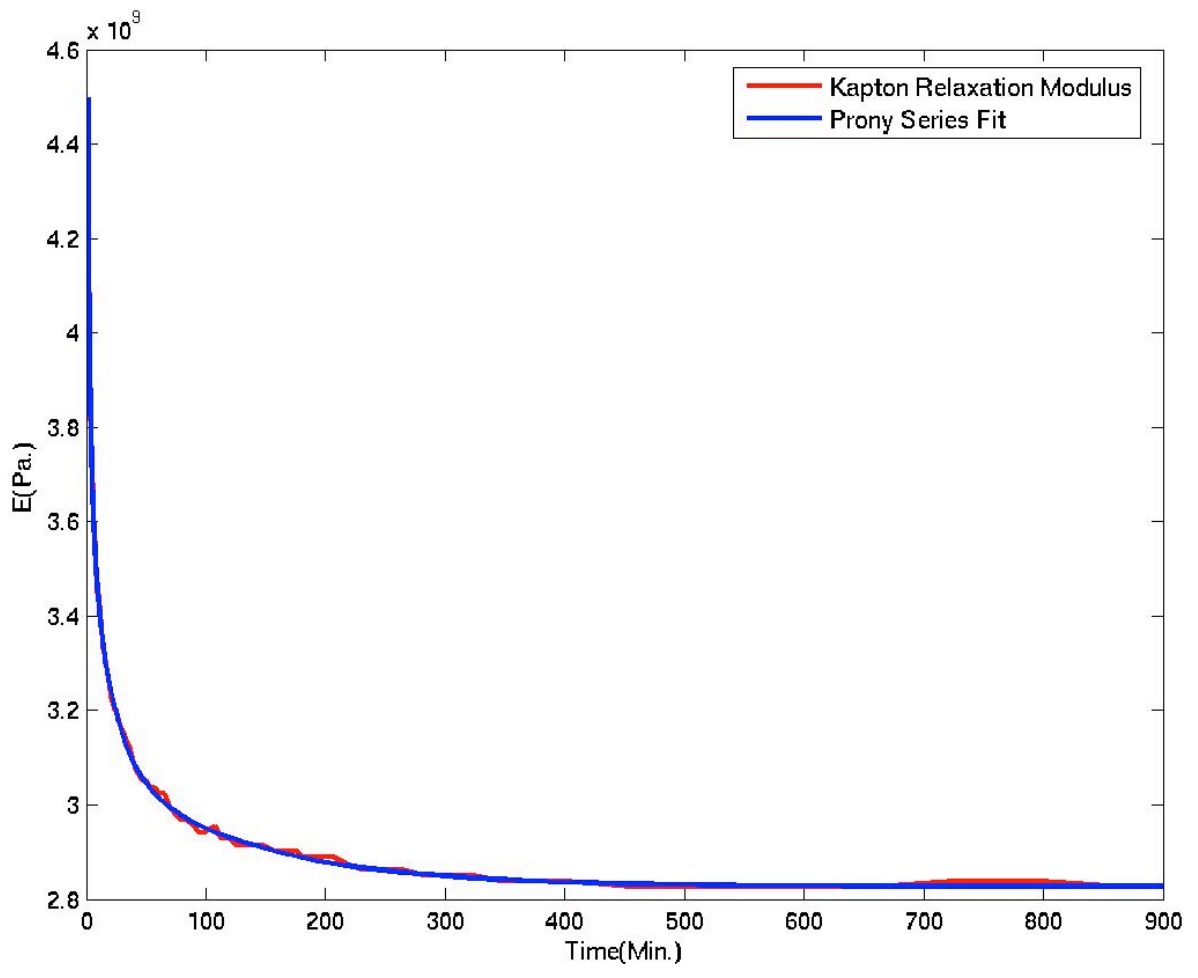

Figure 3.5: Comparison plot of relaxation modulus from reference [26] and Prony series expansion of Kapton ${ }^{\circledR}$. The jagged plot of the Kapton ${ }^{\circledR}$ relaxation modulus at some places is due to the difficulty in manually selecting closely spaced points on a log-log plot while using Digitizeit ${ }^{\circledR}$. 


\section{Chapter 4}

\section{Vibration and Buckling of Vertical Cantilever Tube}

\subsection{Introduction}

The natural frequency of a structure can be identified from the Frequency Response Function plot obtained experimentally. Knowledge of the natural frequencies along with the geometric dimensions can lead us to the determination of equivalent flexural stiffness of the beam assuming that the tube behavior follows Euler-Bernoulli beam theory. The equivalent flexural stiffness is then used to determine the buckling as well as transient response to a given impulse loading. The equivalent flexural stiffness is found for an isotropic material while the actual structure exhibits viscoelastic behavior because ABAQUS ${ }^{\circledR}$ does not find the frequencies for a structure made of a history dependent material.

A Fast Fourier Transform of the experimentally determined velocity-time data reveals the importance of the fundamental natural frequency as shown in Figure 4.1. The other approach used is reduction of the elastic moduli of the carbon strips by a certain fraction to 
account for the sparsity of the fibers so as to match the fundamental frequency and carry out the vibration and buckling analysis for the tube. Although for composites the bending and torsion is generally coupled, the assumption of isotropic material for the tube with equivalent Young's modulus and shear modulus enables to decouple them and study them independently.

\subsection{Equivalent Young's Modulus}

An equivalent value of the Young's modulus is calculated from the experimentally determined Frequency Response Function plots by assuming an equivalent Euler-Bernoulli beam with a tip mass and having the area moment of inertia same as that of the tube specimen.

The following governing equation needs to be solved by taking into account the appropriate boundary conditions.

$$
\frac{d^{4} Y(x)}{d x^{4}}-\frac{\omega^{2} m}{E I} Y(x)=0
$$

which has a general solution of the form

$$
Y(x)=A \sin \beta x+B \cos \beta x+C \sinh \beta x+D \cosh \beta x
$$

The constants A, B, C and D are obtained from the boundary conditions resulting in the following matrix from which consecutive values of $\beta$ are found. The boundary conditions are in the form of clamped end of the tube and a mass attached at the free end. 
$\operatorname{det}\left[\begin{array}{cccc}0 & 1 & 0 & 1 \\ 1 & 0 & 1 & 0 \\ -\sin \beta L & -\cos \beta L & \sinh \beta L & \cosh \beta L \\ -\cos \beta L+\bar{M} \beta L \sin \beta L & \sin \beta L+\bar{M} \beta L \cos \beta L & \cosh \beta L+\bar{M} \beta L \sinh \beta L & \sinh \beta L+\bar{M} \beta L \cosh \beta L\end{array}\right]$

where

$$
\begin{aligned}
& \bar{M}=\frac{M}{m L} \\
& \beta=\sqrt[4]{\frac{\omega^{2} m}{E I}}
\end{aligned}
$$

For the given numerical values of the dimensions of the tube and the tip mass the first value of $\beta$ is found to be 1.027 on solving the above determinant. This value of $\beta$ is used in the frequency expression with the value of $\omega$ being $134.46 \mathrm{rad} / \mathrm{sec}$. as obtained from the experimental results, being the first fundamental frequency. Using the above mentioned relations the equivalent Young's modulus for the tube is found out to be 18.3 GPa.. A model is prepared in the PATRAN ${ }^{\circledR}$ preprocessor for the tube with the given dimensions and tip mass which is used as an input for ABAQUS ${ }^{\circledR}$ for frequency and critical buckling load prediction.

The material properties, equivalent density (based on the total mass of the tube specimen) and Young's modulus of the boom found out to be $1470 \mathrm{Kg} / \mathrm{m}^{3}$ and $18.3 \mathrm{GPa}$. are plugged 


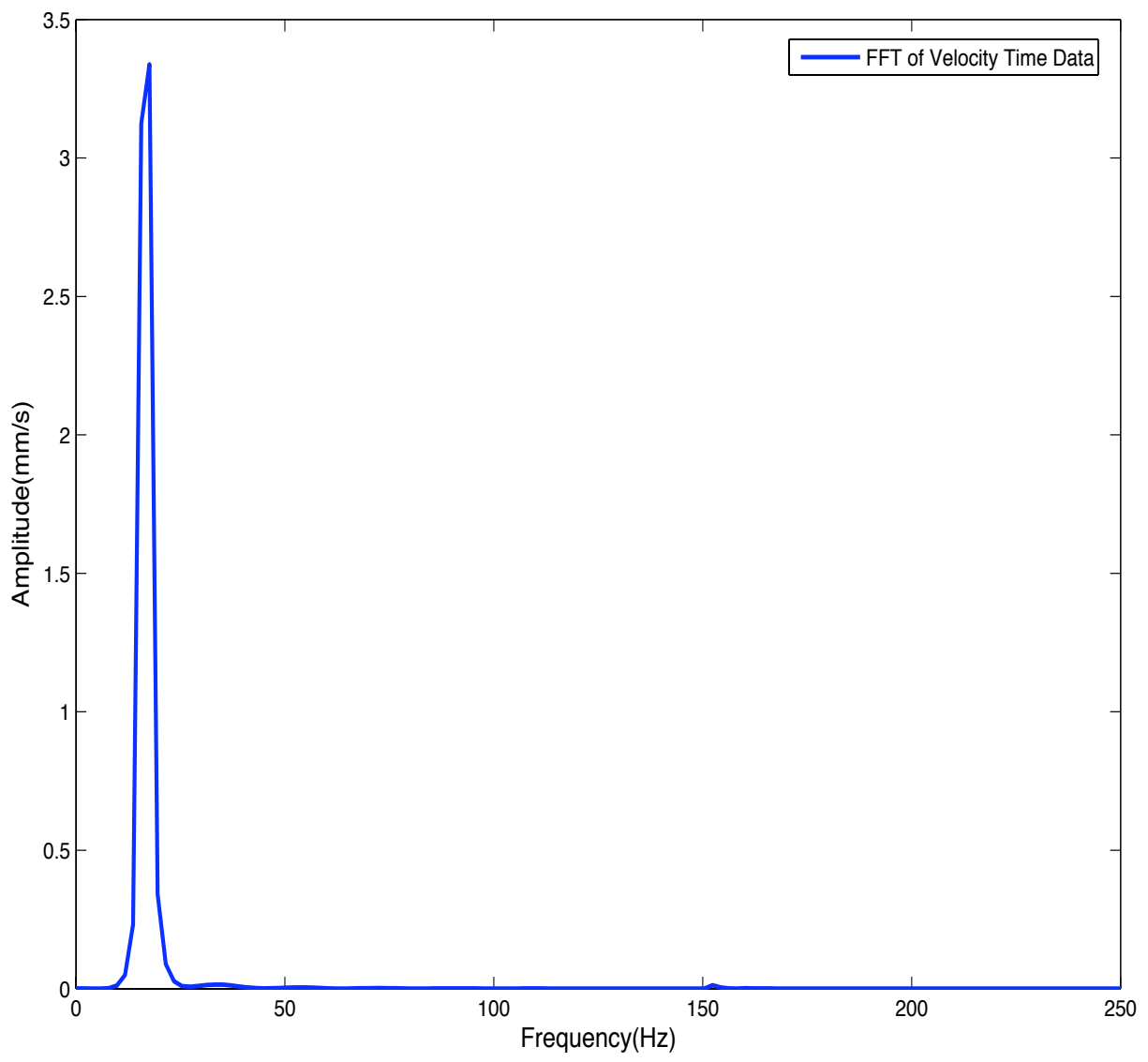

Figure 4.1: Fast Fourier Transform of the velocity time data obtained for a point at the free end of the tube. The peak clearly shows the significance of the fundamental frequency for studying the impulse loading considered in this study. 
Table 4.1: Comparison of the experimental, analytical and numerical values of the natural frequencies corresponding to first three tube bending modes obtained using the equivalent Young's modulus.

\begin{tabular}{|c|c|c|c|}
\hline Beam Bending Mode & Experimental $(\mathrm{Hz})$ & Analytical $(\mathrm{Hz})$ & ABAQUS $^{\circledR}(\mathrm{Hz})$ \\
\hline 1 & 21.4 & 21.4 & 21.4 \\
2 & 196 & 220 & 206 \\
3 & 513 & 688 & 585 \\
\hline
\end{tabular}

in the input files. The mass of the tube is therefore maintained as per the measurements. The fundamental frequency is obtained from ABAQUS ${ }^{\circledR}$ to be $134.46 \mathrm{rad} / \mathrm{sec}$ as desired while the critical buckling load comes out to be $4607.64 \mathrm{~N}$. To check for the bending modes of the tube a $1 \mathrm{D}$ beam model with a tip mass is also prepared and analyzed in ABAQUS ${ }^{\circledR}$ for the mode shapes. A close match between the bending modes for the beam and for the tube is obtained as shown in Figure 4.2. The natural frequencies other than those corresponding to the bending modes also come out to be quite close to the various peaks in the Frequency Response Function plot. The first three bending mode frequencies obtained using the equivalent Young's modulus are close to those obtained experimentally, as shown in Table 4.1 .

\subsection{Equivalent Shear Modulus}

The value of shear modulus is found from the following relationship for an isotropic material.

$$
G=\frac{E}{2(1+\nu)}
$$


1-D Beam
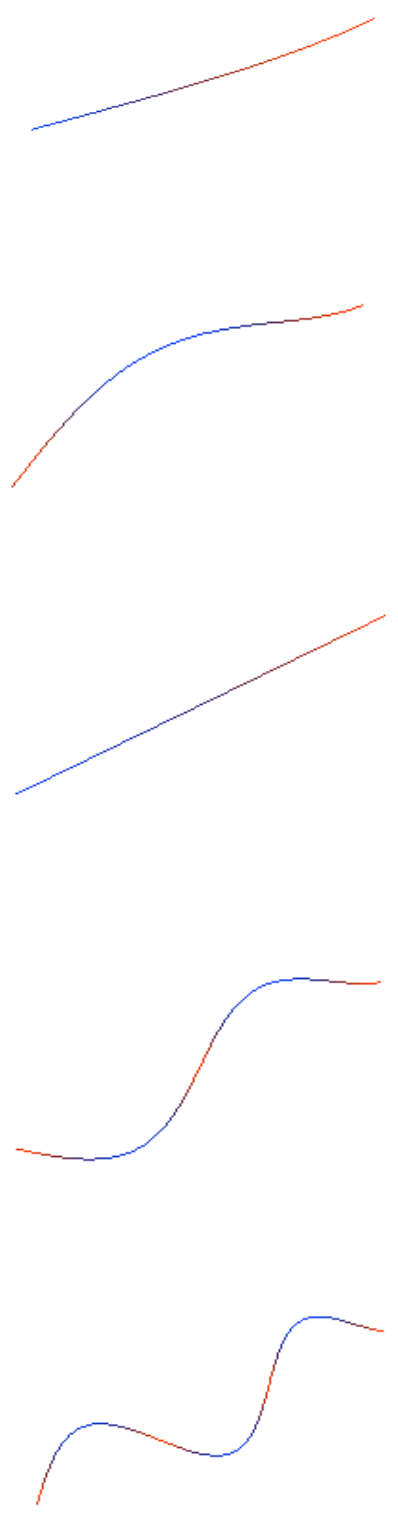

Tube

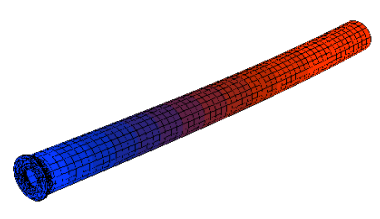

Mode 1

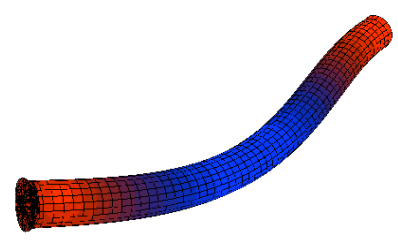

Mode 2

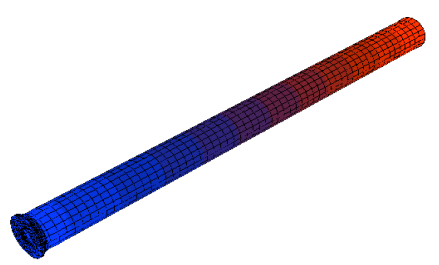

Mode 3

Mode 4
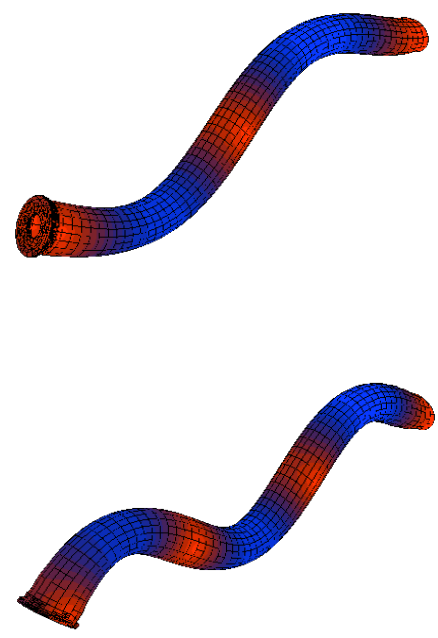

Mode 5

Figure 4.2: Comparison of mode shapes obtained for the tube modeled with shell elements as well as a 1D beam elements with tip masses. 


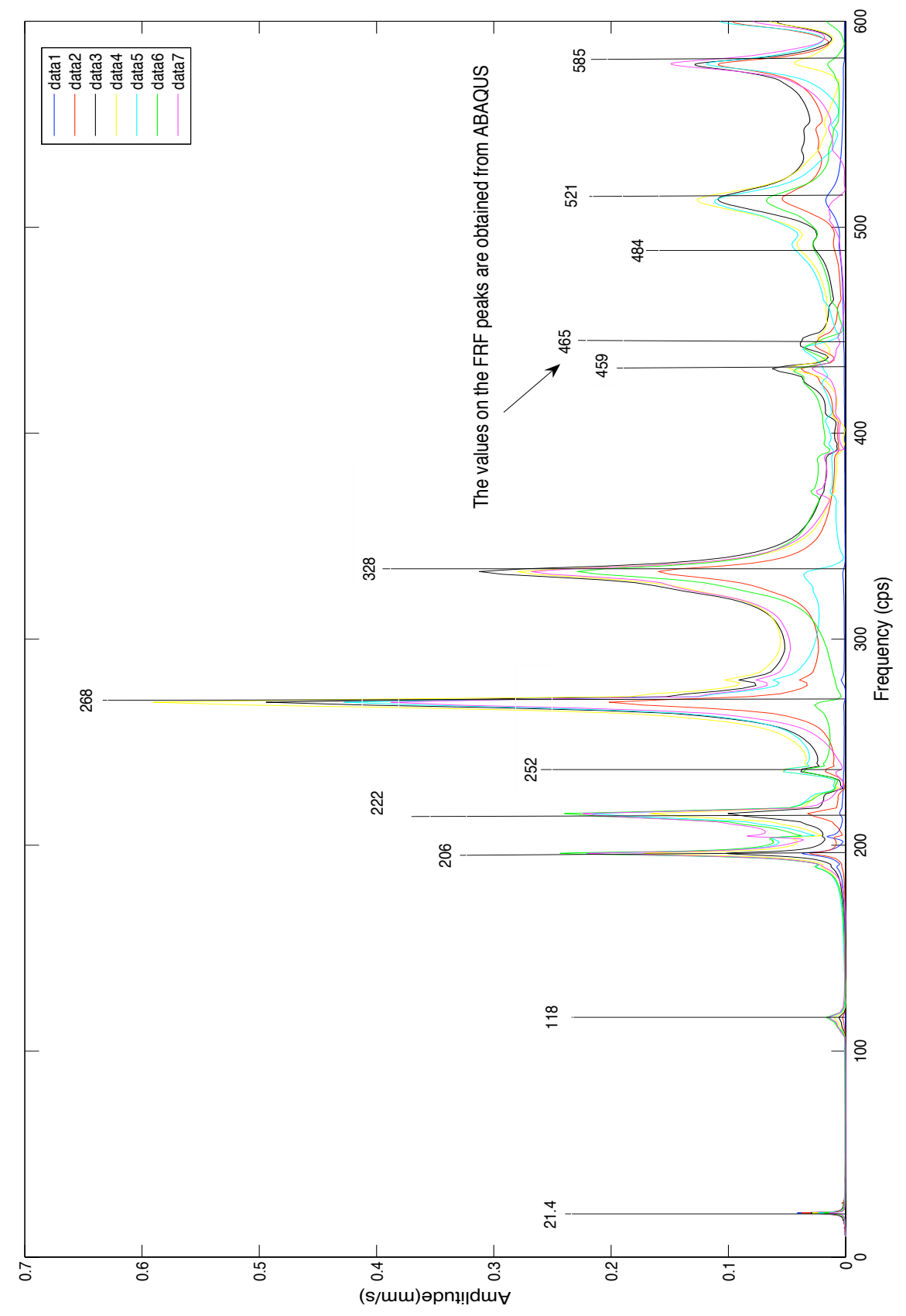

Figure 4.3: Comparison of the frequencies from the experimental Frequency Response Function and ABAQUS ${ }^{\circledR}$ for equivalent value of the Young's modulus. Assumption of equivalent Young's modulus for the tube based on fundamental natural frequency also gives the higher values of natural frequencies in close agreement to the ones experimentally found out. 
Table 4.2: Comparison of the experimental and numerical values of the natural frequencies other than the bending modes obtained using the equivalent Young's modulus.

\begin{tabular}{|c|c|c|c|}
\hline Number & Experimental $(\mathrm{Hz})$ & ABAQUS $^{\circledR}(\mathrm{Hz})$ & \%Error $=\frac{\mid \text { Experimental }-A B A Q U S \mid}{\text { Experimental }} \times 100$ \\
\hline 1 & 21.4 & 21.4 & 0 \\
2 & 116 & 118 & 1.724 \\
3 & 196 & 206 & 5.102 \\
4 & 215 & 222 & 3.26 \\
5 & 235 & 252 & 7.234 \\
6 & 269 & 268 & 0.37 \\
7 & 333 & 328 & 1.50 \\
8 & 432 & 459 & 6.25 \\
9 & 444 & 465 & 4.73 \\
10 & 491 & 584 & 1.425 \\
11 & 513 & 585 & 1.56 \\
12 & 579 & & 1.036 \\
\hline
\end{tabular}

For an equivalent value of Young's modulus of $18.6 \mathrm{GPa}$. the equivalent value of $\mathrm{G}$ is 6.8 GPa. for an average value of Poissons ratio of 0.34 for Kapton ${ }^{\circledR}$ [26]. The torsional frequency of a thin tube with a tip mass is determined from the following relation

$$
\frac{d^{2} \theta(x)}{d x^{2}}+\omega^{2} \frac{\rho}{G} \theta(x)=0
$$

where $\theta$ is the angular twist of the tube and is a function of the length and $\rho$ is the density of the tube material. Solution of the above equation is given by

$$
\theta(x)=A \sin \beta x+B \cos \beta x
$$


where

$$
\beta=\omega \sqrt{\frac{\rho}{G}}
$$

and constants A and B are found from the boundary conditions. For clamped end $\theta(x)=0$ at $\mathrm{x}=0$ while for the tip-loaded free end at $\mathrm{x}=\mathrm{L}$ the boundary condition becomes

$$
G I_{p} \frac{d \theta(x)}{d x}=I_{0} \omega^{2} \theta(x)
$$

While B is zero using the first boundary condition, A gets eliminated in the second one. Considering the physical parameters of the tube the following transcendental equation need be solved for consecutive values of $\beta$.

$$
\beta \tan (\beta L)-\frac{I_{p} \rho}{I_{0}}=0
$$

Consecutive values of $\beta$ thus obtained are listed in Table 4.3. For our case assuming the tip mass in the form of a metallic disc attached at the end of the tube other dimensions remaining the same, the fundamental torsional frequency is obtained to be $309 \mathrm{~Hz}$ which is close to the one obtained from ABAQUS ${ }^{\circledR}$. The successive values of $\beta$, the corresponding analytical frequencies and ones from ABAQUS ${ }^{\circledR}$ are shown in the Table 4.3.

Another case to validate the value of $\mathrm{G}$ was run for a thin tube of same dimensions and end conditions without the tip mass. The results from ABAQUS ${ }^{\circledR}$ were checked against the commonly occurring analytical results where for a free-clamped tube the following 

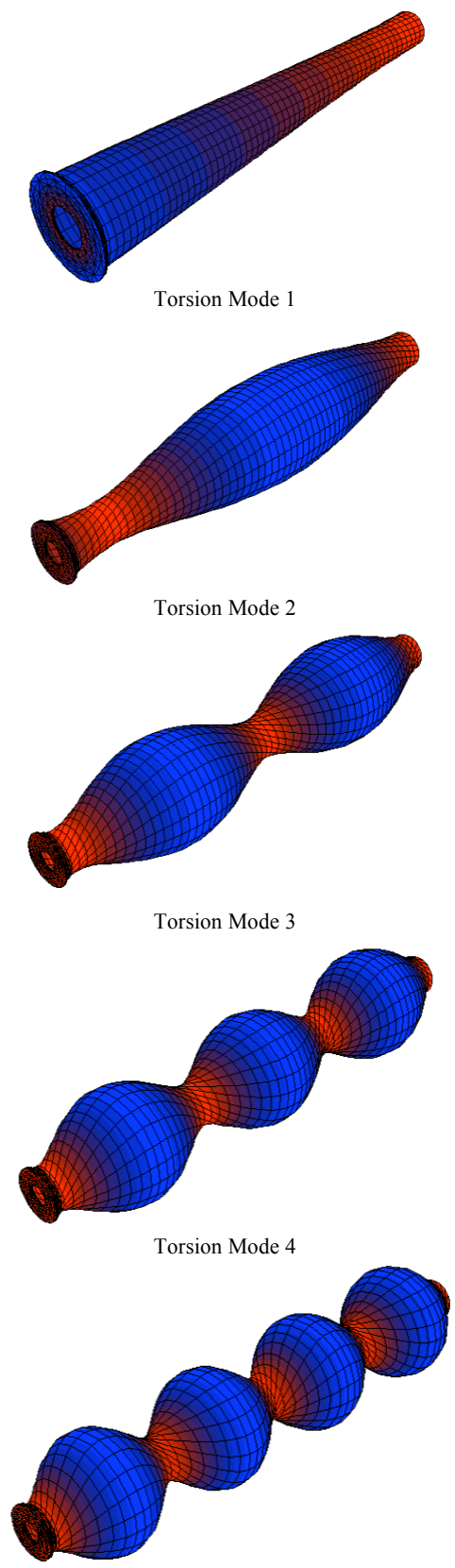

Torsion Mode 5

Figure 4.4: Consecutive torsion modes for an equivalent value of shear modulus of 6.8 GPa.. 
Table 4.3: Comparison of the values of torsional frequencies obtained from analytical results with those from ABAQUS ${ }^{\circledR}$ for a tube with tip mass.

\begin{tabular}{|c|c|c|c|}
\hline Torsion Mode & $\beta$ & Analytical $(\mathrm{Hz})$ & ABAQUS $^{\circledR}(\mathrm{Hz})$ \\
\hline 1 & 0.893734 & 309 & 311 \\
2 & 3.00673 & 1039 & 1146.5 \\
3 & 5.41716 & 1873 & 2122.9 \\
4 & 7.92443 & 2740 & 3133 \\
5 & 10.4666 & 3613 & 4158.9 \\
\hline
\end{tabular}

transcendental equation need be solved for $\beta$

$$
\beta \cos \beta L=0
$$

and plugged back in the following equation for determining the frequencies.

$$
\beta=\omega \sqrt{\frac{\rho}{G}}
$$

A comparison is again made in Table 4.4 between the values of torsional frequencies obtained from the analytical results for a clamped-free tube and that given by ABAQUS ${ }^{\circledR}$ for the elastic material with the equivalent value of $\mathrm{E}$ found earlier.

\subsection{Transient Response}

At the beginning of the study it was thought that the viscoelastic material Kapton ${ }^{\circledR}$ which 
Table 4.4: Comparison of the values of torsional frequencies obtained from analytical results with those from ABAQUS ${ }^{\circledR}$ for a tube without tip mass

\begin{tabular}{|c|c|c|c|}
\hline Torsion Mode & $\beta$ & Analytical $(\mathrm{Hz})$ & ABAQUS $^{\circledR}(\mathrm{Hz})$ \\
\hline 1 & 1.28176 & 443 & 441 \\
2 & 3.84528 & 1329 & 1325 \\
3 & 6.4088 & 2215 & 2210 \\
4 & 8.97232 & 3101 & 3098 \\
5 & 11.5358 & 3987 & 3991 \\
\hline
\end{tabular}

is one of the components of which the tube structure is made of, was solely responsible for the high value of damping observed experimentally. Consequently a shell model of the physical structure was made with the tube boom made of layers of carbon with the lay up as shown in Figure 3.2 and constrained with Kapton ${ }^{\circledR}$. To replicate the experimental load application to the tube the input impulse function was incorporated into the input file as a time varying load at a node on the cap and the velocity was measured at the node diametrically opposite to the point of impulse load application as shown in Figure 4.5. At this time however no account of the sparsity of the carbon fibers was considered, the purpose of the analysis being to see the effect of Kapton ${ }^{\circledR}$ on damping. Figure 4.6 shows little to no effect of Kapton ${ }^{\circledR}$ on the damping and matches poorly with the actual experimental velocity-time plot. Kapton $^{\circledR}$ viscoelasticity playing no role in the damping necessitated the use of experimentally determined Rayleigh parameters to be used in the numerical analysis.

The Rayleigh assumption states that the viscous matrix can be approximated as a linear 
combination of mass and stiffness matrices or mathematically as,

$$
[C]=\alpha[M]+\beta[K]
$$

where $\alpha$ and $\beta$ are the constants determined from the Frequency Response Function plots as described in Appendix A. 3D shell models for the tube are computationally expensive with long run times, consequently in order to have quick results the $1 \mathrm{D}$ beam models of the tube are also made replicating its area moment of inertia and end conditions and loaded with the tip mass. The value of the tip mass was provided by ILC Dover, the fabricator of the tube. The boom density corresponding to the total weight of the specimen is determined and the experimentally determined values of Rayleigh Damping parameters (refer Appendix A) are used to determine the dynamic response of the tube. Modeling the tube as a beam is easier and takes much less time for the dynamic analysis and gives an accurate first hand information regarding the dynamics and natural frequencies as opposed to the actual tube structure . It was found that for the tip mass of $0.207 \mathrm{~kg}$ the first peak of the numerical response did not match well with the experimental velocity time output. Neither did the values of the Rayleigh Damping parameters had much of a role to play in the system damping as evident from Figure 4.7. Consequently the 1D beam was loaded with lower and lower tip mass values with a corresponding reduction in equivalent value of the Young's modulus, the criteria being that the fundamental frequency matches with that determined experimentally. Artificial damping is assumed to depend only on the mass 

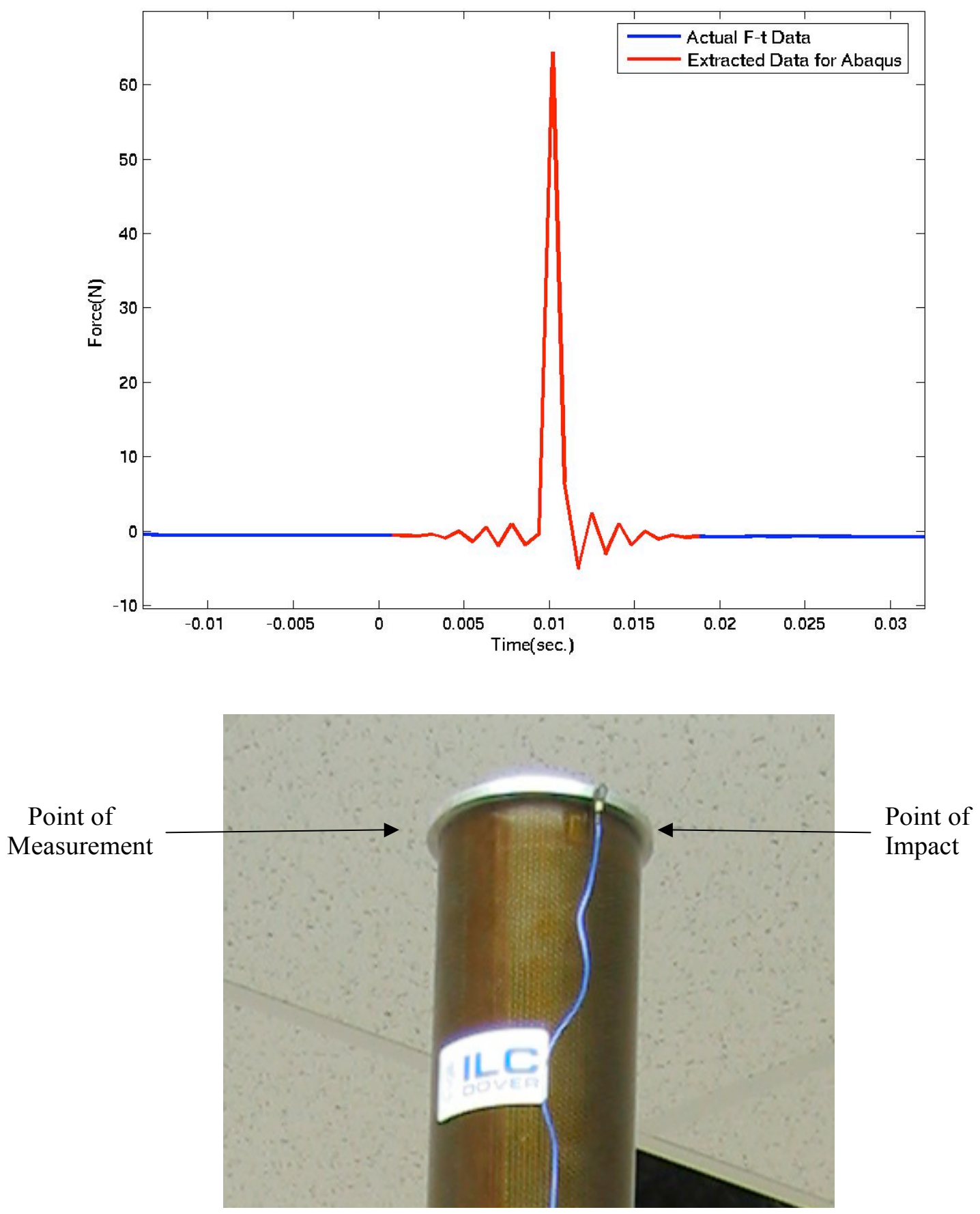

Figure 4.5: Impulse force function. 


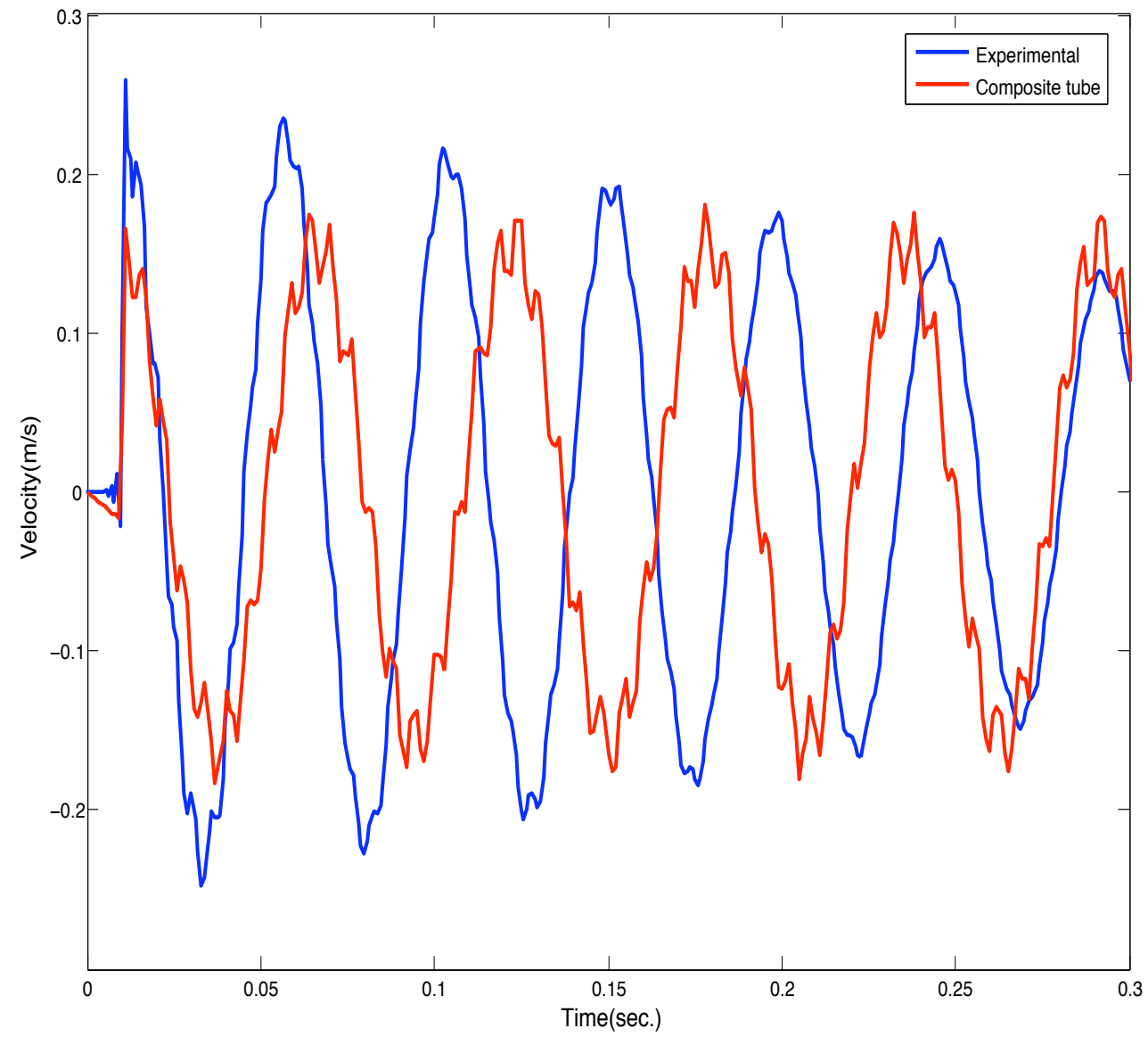

Figure 4.6: Velocity-time plot comparison of the experimental output and of a shell model in ABAQUS ${ }^{\circledR}$ with a tip mass of $0.207 \mathrm{Kg}$ and viscoelastically constrained carbon laminas with actual orthotropic elastic material properties. 
Table 4.5: Comparison of the experimental and numerical values of the natural frequencies corresponding to the first three tube bending modes obtained using the estimated equivalent Young's modulus and tip mass.

\begin{tabular}{|c|c|c|}
\hline Beam Bending Mode & Experimental $(\mathrm{Hz})$ & ABAQUS $^{\circledR}(\mathrm{Hz})$ \\
\hline 1 & 21.4 & 21.4 \\
2 & 196 & 193 \\
3 & 513 & 517 \\
\hline
\end{tabular}

matrix consequently the $\alpha$ of the Rayleigh equation is estimated while $\beta$ is assumed to be zero and the analysis is carried out. The response matches closely with the experimental output as observed in Figure 4.8.

The dynamics of the elastic tube with reduced value of tip mass $(0.145 \mathrm{Kg}$. $)$ and elastic modulus is also compared with the experimental output. The results match quite well as evident from Figure 4.9.

After observing the dynamic response of the 1D beam with reduced mass, an ABAQUS ${ }^{\circledR}$ run was also attempted on the original tube by changing the tip mass and incorporating the composite laminas but reducing the value of orthotropic elastic properties of carbon by a certain percentage to account for the sparsity of the carbon strips in the actual specimen and obtaining close agreement between the values of the fundamental frequency as obtained by numerical and experimental approaches. Sufficiently good agreement was achieved as seen in Figure 4.10. Table 4.6 gives the estimated values of the elastic characteristics, damping parameters and the tip mass used in the numerical analysis that gave good match with the experimental dynamic outputs. Very close agreement between the numerical 


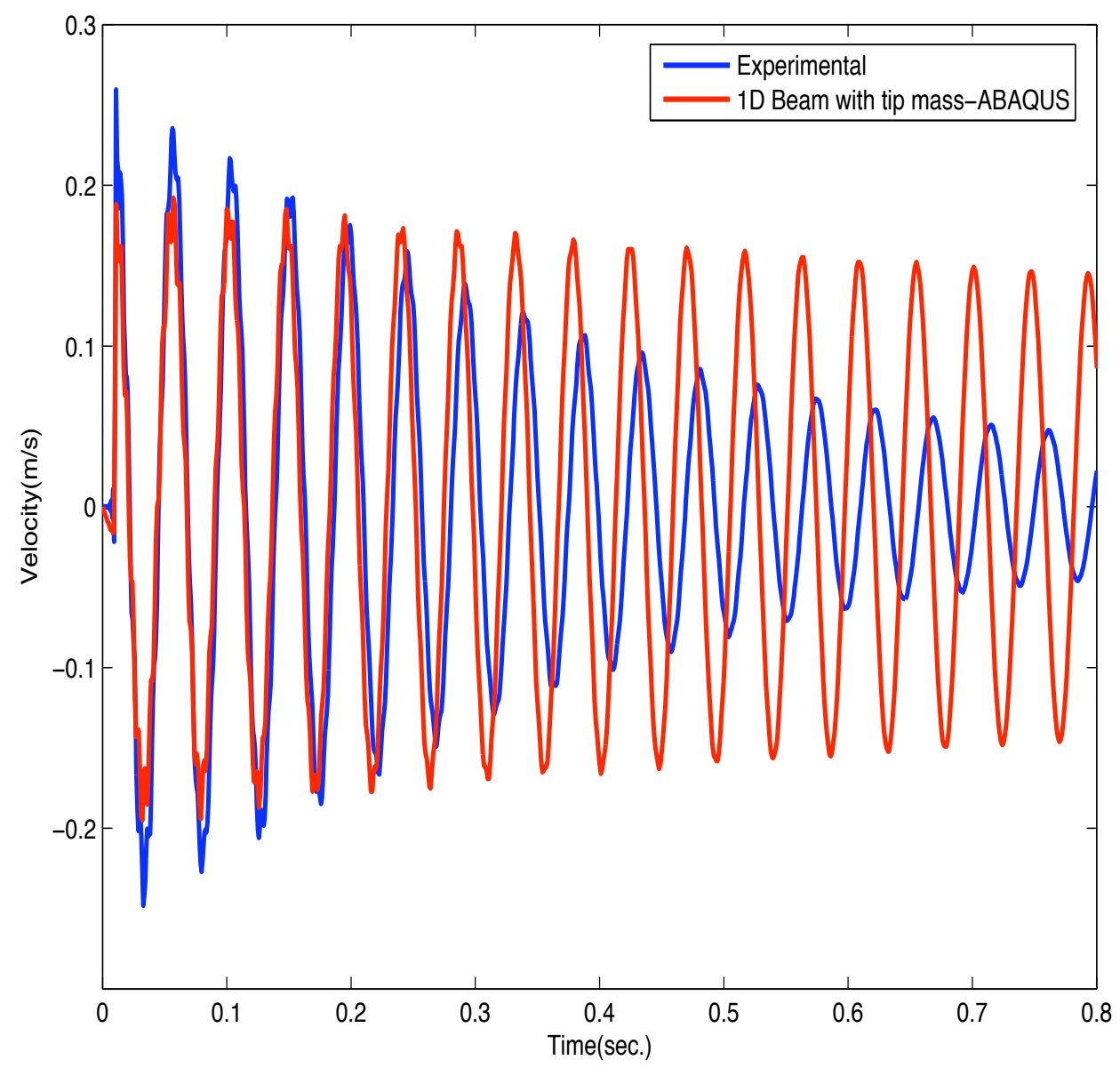

Figure 4.7: Velocity time plot comparison of the experimental output and ABAQUS ${ }^{\circledR}$ generated 1D beam with equivalent Young's modulus of $18.6 \mathrm{GPa}$. and experimentally determined Rayleigh parameters $\alpha=2.62 ; \beta=0.0000051$. 


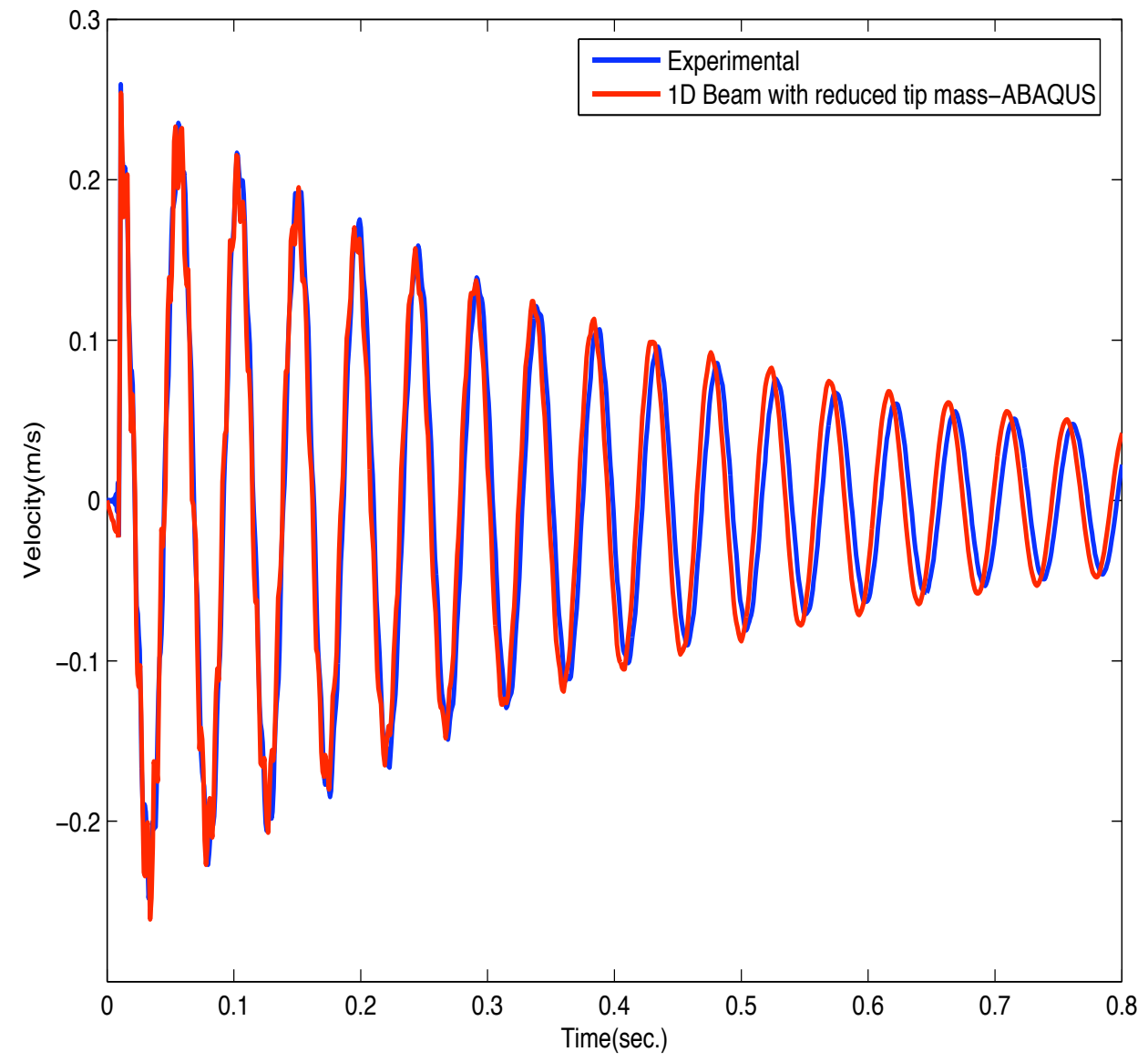

Figure 4.8: Velocity time plot comparison of the experimental output and ABAQUS ${ }^{\circledR}$ generated results for a $1 \mathrm{D}$ beam with reduced tip mass, estimated equivalent Young's modulus and estimated Rayleigh parameters. 


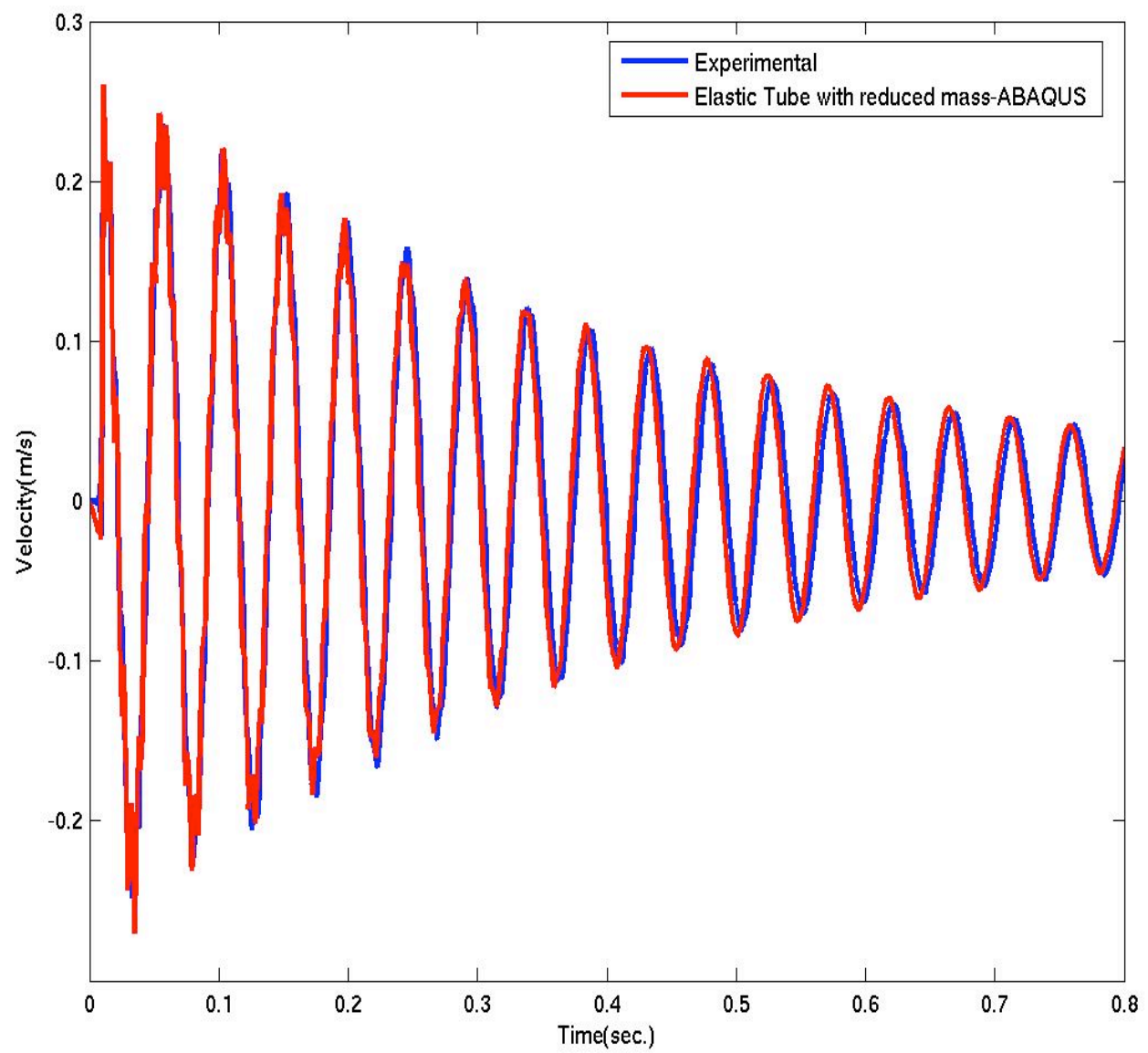

Figure 4.9: Velocity time plot comparison of experimental output and ABAQUS ${ }^{\circledR}$ generated results for an elastic tube with reduced tip mass, estimated equivalent Young's modulus and estimated Rayleigh parameters. 
Table 4.6: Estimated values of the parameters.

\begin{tabular}{|c|c|c|}
\hline Parameter & Initial Value & Estimated Value \\
\hline Equivalent Young's Modulus & $18.3 \mathrm{GPa}$. & $13.5 \mathrm{GPa}$. \\
\hline Tip Mass & $0.207 \mathrm{Kg}$. & $0.145 \mathrm{Kg}$. \\
\hline \multirow{3}{*}{ Orthotropic Elastic Properties $\left(\mathrm{kN} / \mathrm{mm}^{2}\right)$} & $\mathrm{E}_{11}=135$ & $\mathrm{E}_{11}=37.46$ \\
& $\mathrm{E}_{22}=13$ & $\mathrm{E}_{22}=3.60$ \\
& $\mathrm{G}_{12} \& \mathrm{G}_{13}=6.4$ & $\mathrm{G}_{12} \& \mathrm{G}_{13}=1.77$ \\
& $\mathrm{G}_{23}=4.3$ & $\mathrm{G}_{23}=1.19$ \\
\hline \multirow{2}{*}{ Rayleigh Parameters } & $\alpha=2.62$ & $\alpha=18$ \\
& $\beta=0.0000051$ & $\beta=0$ \\
\hline
\end{tabular}

results and experimental ones is important if the tube is to be used for predicting the responses to more arbitrary loadings. Here it is worthwhile to mention that extensive node and time convergence studies were carried out on the beam and shell numerical models of the actual tube specimen. Minimum values of time step and number of elements required for sufficiently good accuracy without making the analysis computationally expensive were found and used throughout the analysis. Figures 4.12 and 4.13 show the comparison of responses for the models used for carrying out the analysis in this study and the responses of some models constructed with greater number of elements with all other parameters such as geometric dimensions, material properties, damping values and boundary conditions remaining constant.

\subsection{Critical Buckling}

Critical Buckling load for the specimen is found for the equivalent value of the Young's 


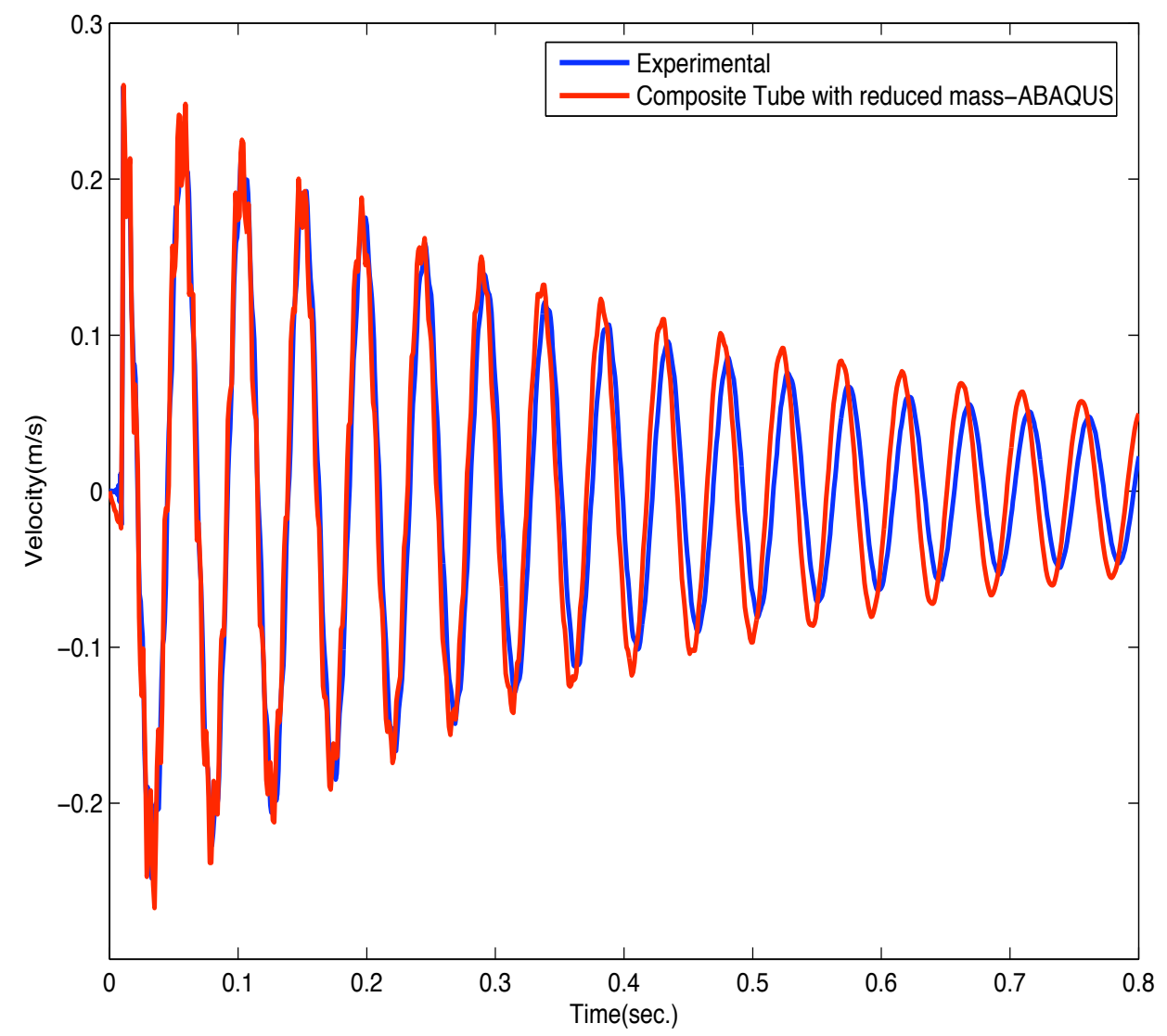

Figure 4.10: Velocity Time Plot comparison of the experimental output and ABAQUS ${ }^{\circledR}$ modeled composite tube with reduced tip mass and material properties. 


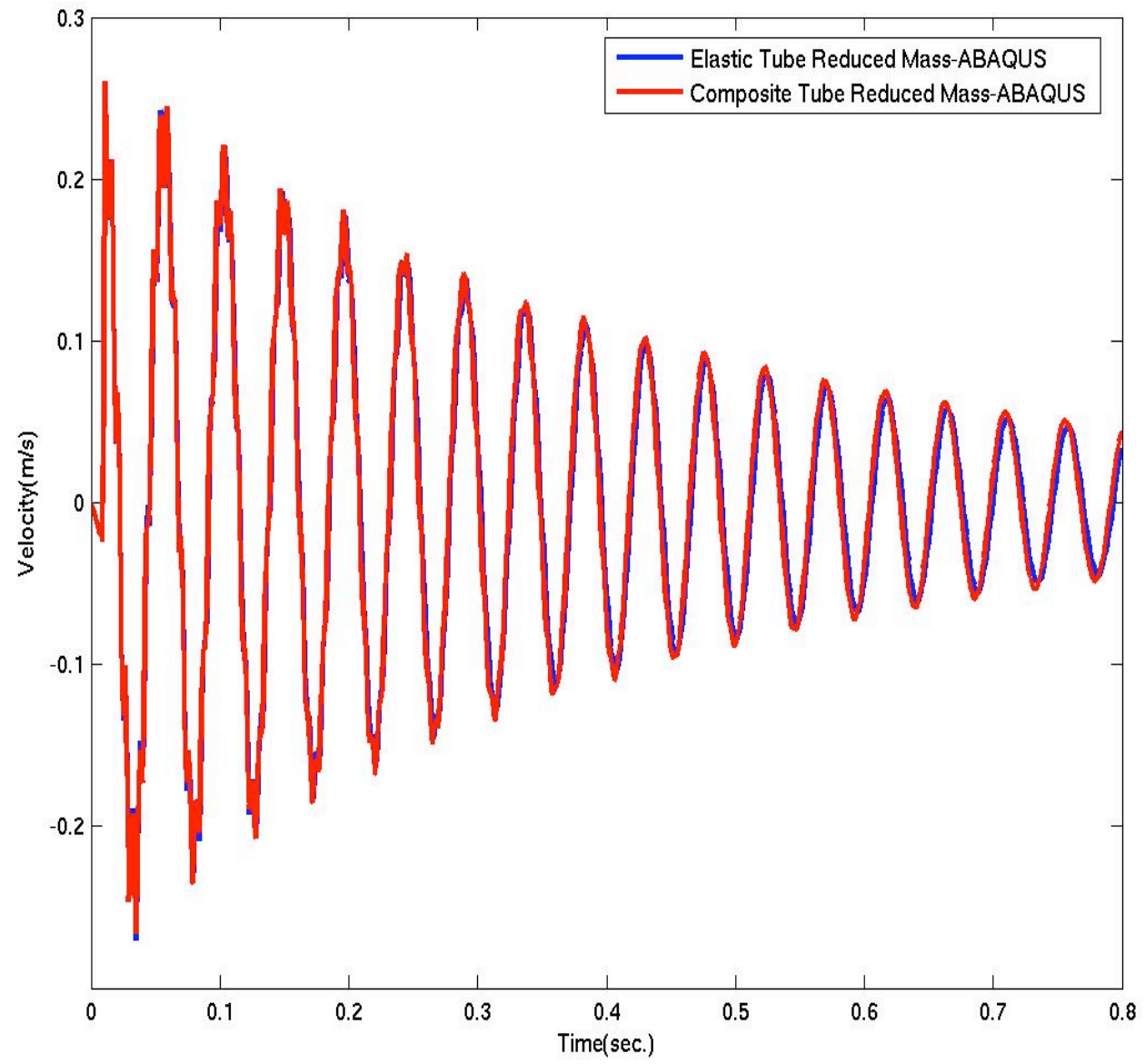

Figure 4.11: Velocity time plot comparison of the elastic tube with a value of Young's modulus of $13.5 \mathrm{GPa}$. and a composite tube with same geometric configuration having elastic modulus reduced by some percentage. 


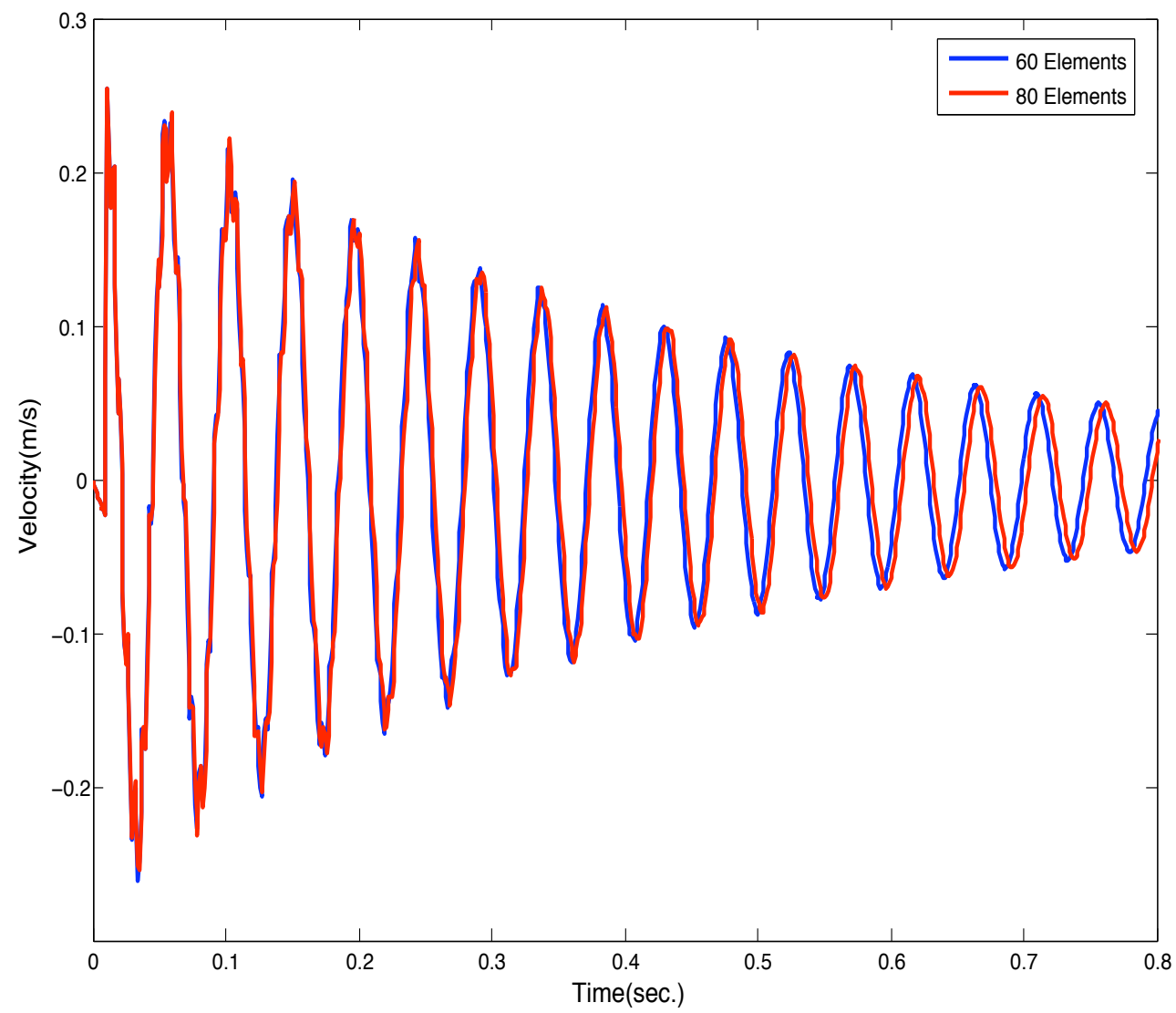

Figure 4.12: Node Convergence study for the 1D beam. Estimated values of Young's modulus, tip mass and Rayleigh parameters are used for numerically generating the responses of two models having different number of elements. 


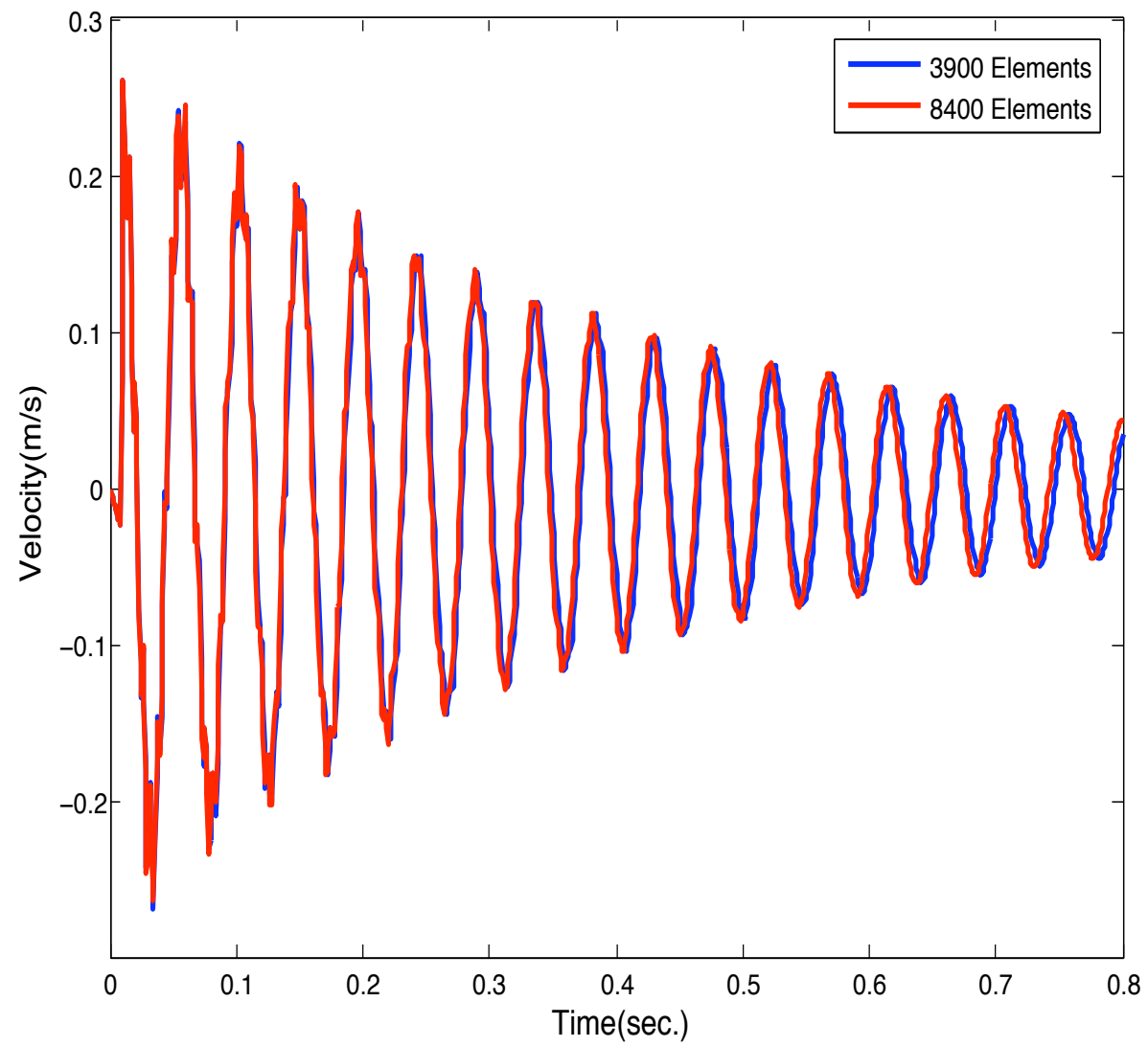

Figure 4.13: Node Convergence study for the shell model. Estimated values of Young's modulus, end cap mass and Rayleigh parameters are used for numerically generating the responses of two models having different number of elements. 
modulus as determined from the experimental data and also for the reduced modulus value. Buckling analysis is also done for the tube specimen as a composite structure, with the elastic properties of carbon strips reduced by some percentage. Good agreement was seen in the results given by ABAQUS ${ }^{\circledR}$ and the analytical results. The analytical expression for the critical buckling of a column in a fixed-free configuration (when the critical buckling mode of the tube is like a column) is given by [28]

$$
P_{c r}=\frac{\pi^{2} E I}{4 L^{2}}
$$

while the critical buckling load for a thin isotropic cylindrical shell with loads applied at both ends is given by [28]

$$
\sigma_{c r}=\frac{E h}{a \sqrt{3\left(1-\nu^{2}\right)}}
$$

Buckling values for a clamped-free tube with estimated equivalent value of Young's modulus and composite tube of same dimensions and end conditions using the estimated orthotropic material properties so as to match the fundamental frequency and the dynamic response were also found. 
Table 4.7: Critical buckling loads without end mass.

\begin{tabular}{|c|c|c|c|c|}
\hline Specimen & Length $(\mathrm{m})$ & E (GPa.) & Analytical (N) & ABAQUS (N) \\
\hline 1 & 1.219 & 18.3 & 3129 & 3378 \\
2 & 1.219 & 13.5 & 2342 & 2529 \\
3 & 1.219 & Composite & - & 2332 \\
4 & 3 & 18.3 & 787 & 760 \\
5 & 3 & 13.5 & 589 & 571 \\
6 & 3 & Composite & - & 590 \\
\hline
\end{tabular}

Table 4.8: Buckling load values for an isotropic tube and a composite one both having the same fundamental frequency.

\begin{tabular}{|c|c|c|}
\hline Mode Number & Composite Tube (N) & Isotropic Tube (N) \\
\hline 1 & 2320 & 2520 \\
2 & 3080 & 3380 \\
3 & 3440 & 3400 \\
4 & 3620 & 4000 \\
5 & 3800 & 4160 \\
\hline
\end{tabular}



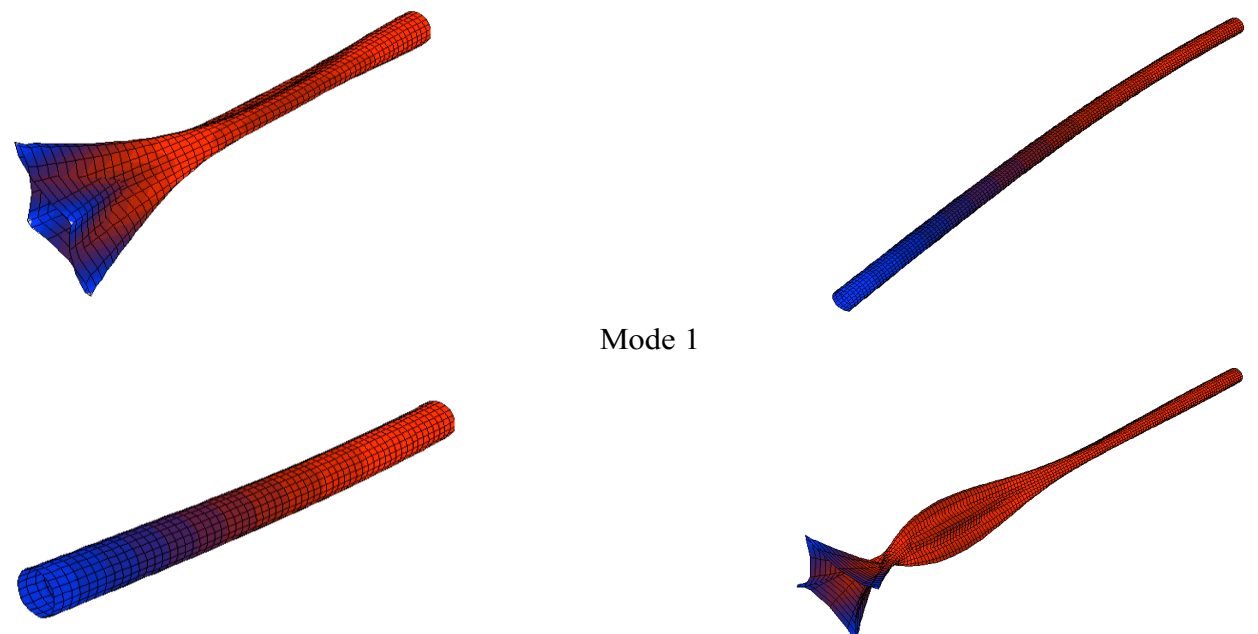

Mode 1
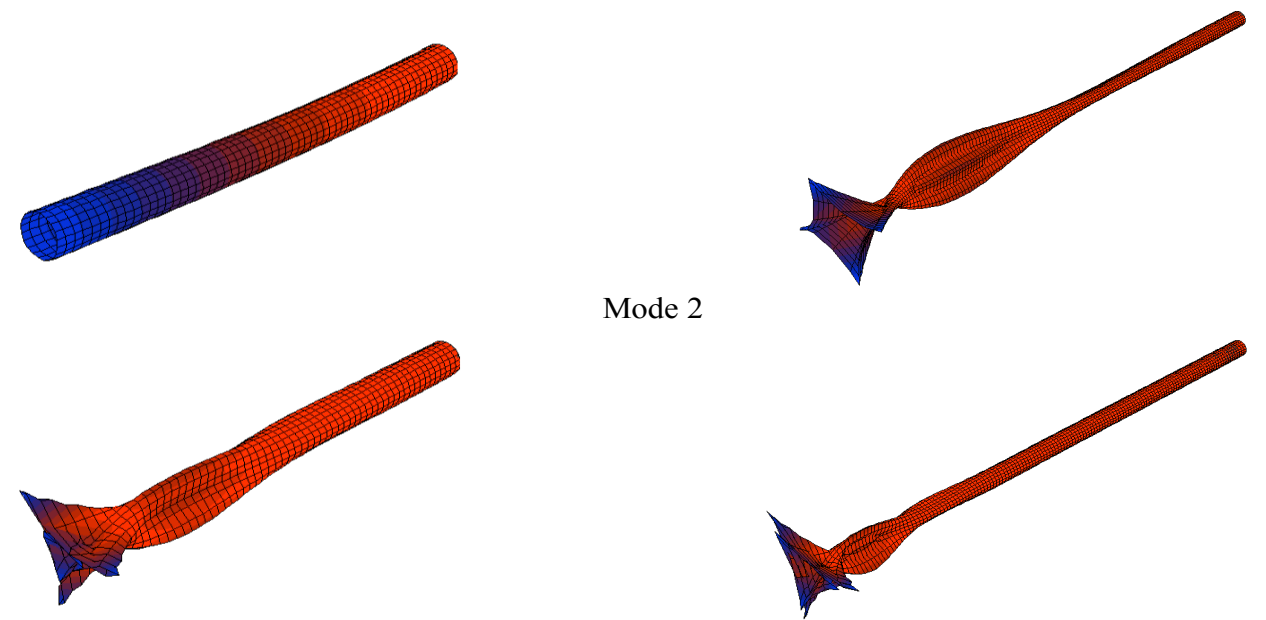

Mode 2

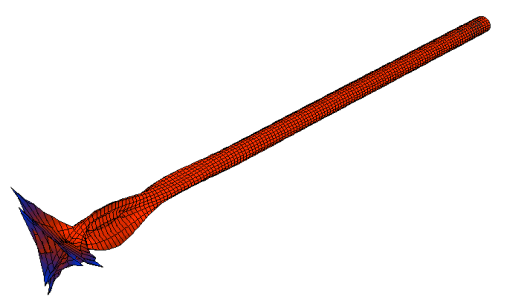

Mode 3
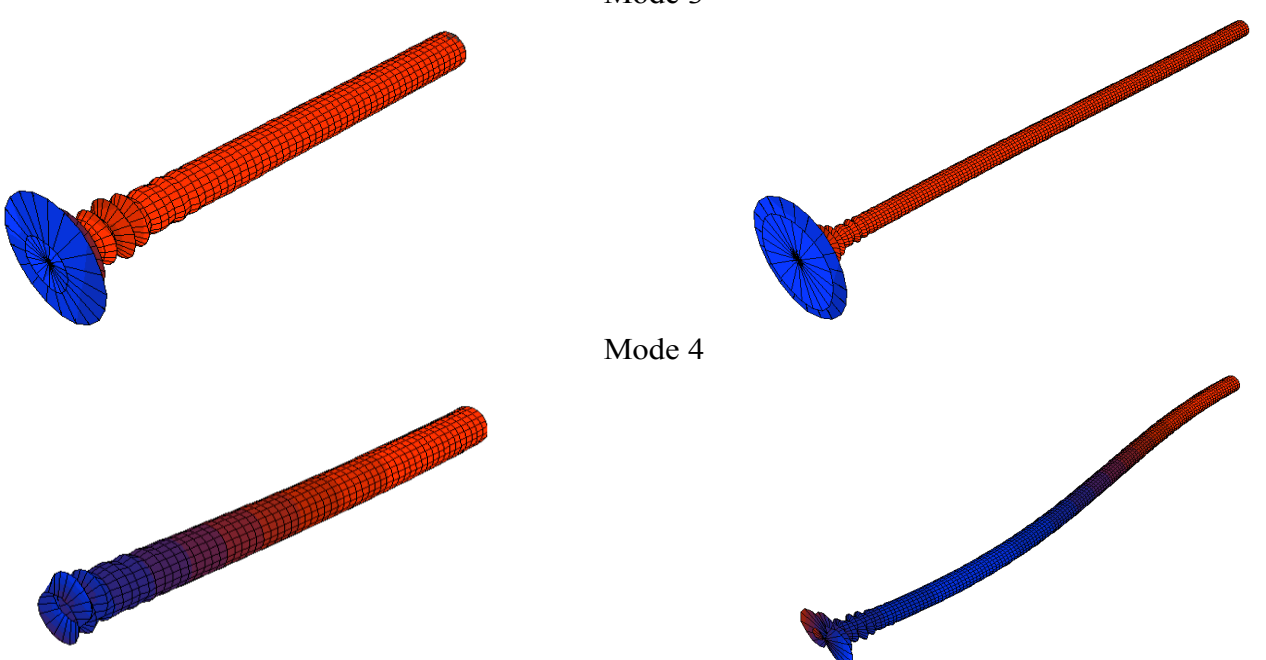

Mode 4

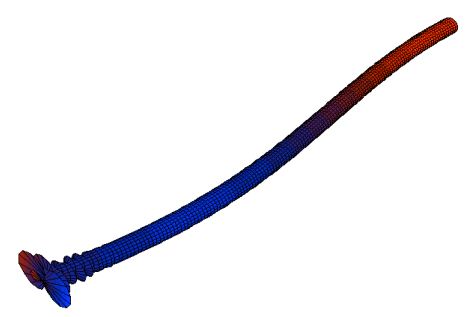

Mode 5

Figure 4.14: First five buckling modes for the isotropic tube with equivalent Young's modulus for lengths of $1.219 \mathrm{~m}$.(left) and $3 \mathrm{~m}$.(right). 

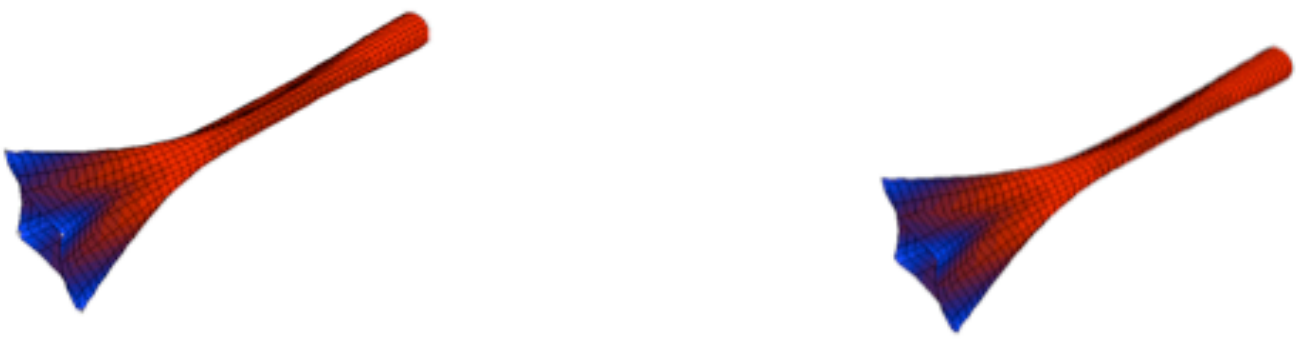

Mode 1
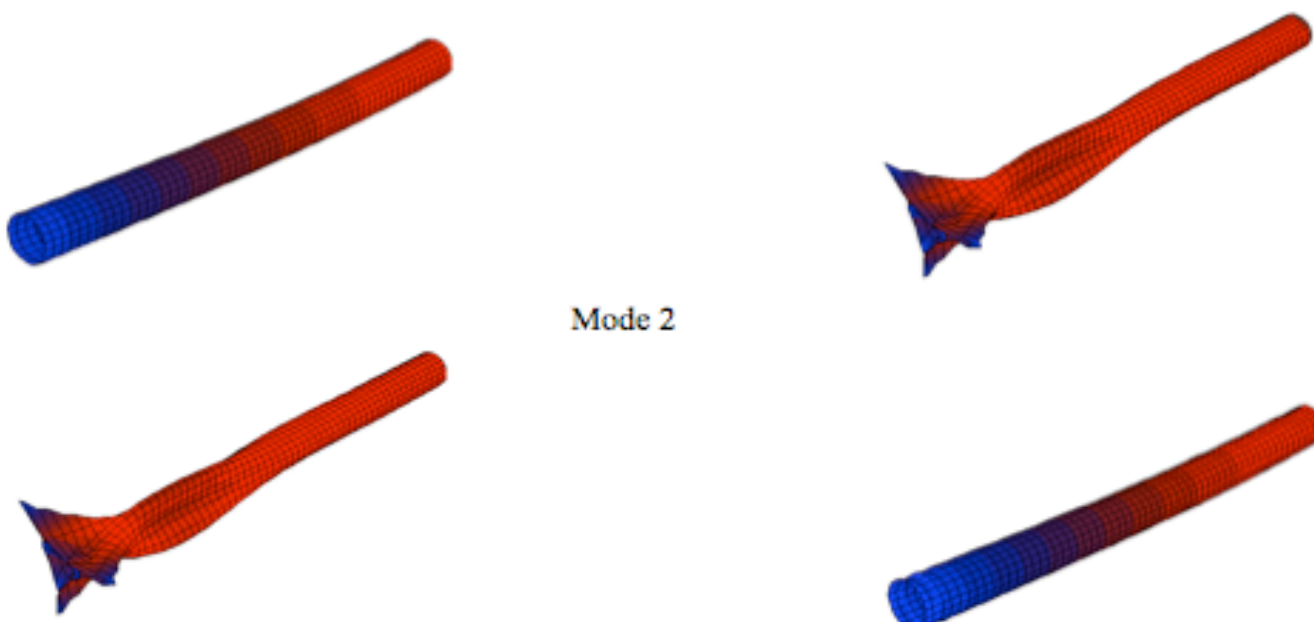

Mode 2

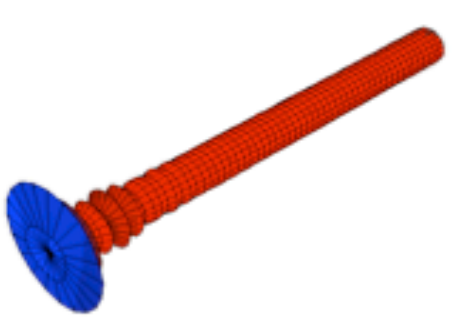

Mode 3
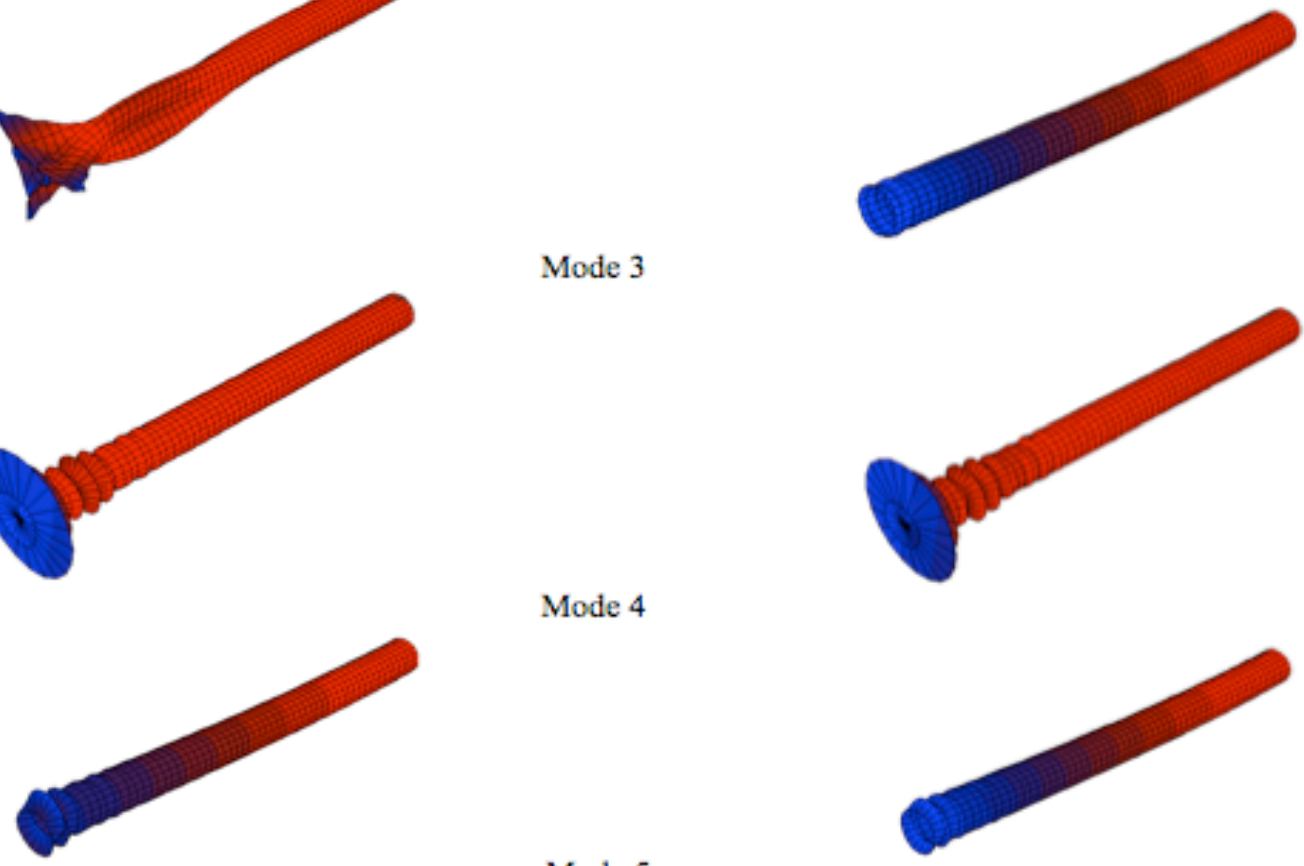

Mode 4

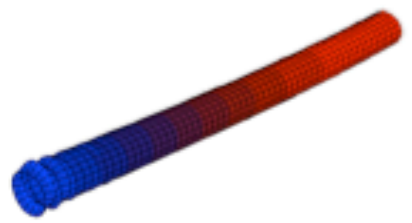

Mode 5

Figure 4.15: Comparison of the buckling mode shapes of an isotropic tube of estimated equivalent value of Young's modulus (left) and a composite tube with estimated values of the orthotropic material properties (right). 


\subsection{Natural Frequency and Buckling Analysis of a Ten Bay Truss}

Truss construction for space applications calls for assembling repeating elements made up of battens, longerons and diagonals such as one shown in Figure 5.1. These repeating elements are attached in series to form the complete truss with desired dimensions and material specifications.

The composite boom being investigated in this study will form an integral member of a truss as a batten, longeron or a diagonal. Such a truss has not been built and tested as yet. The importance of the current study lies in the extension of the boom as a integral member of the truss and checking for its dynamics, buckling loads, frequencies and mode shapes numerically. It is very easy numerically to construct a three dimensional truss composed of 1D beam elements and checking its frequencies and critical buckling loads as compared to constructing actual specimens and testing them experimentally. Numerical modeling also provides design flexibility.

The modeling of the truss as $1 \mathrm{D}$ beam elements would save computation time and will give a good first hand information on its response. The dynamics can also be easily incorporated by subjecting the truss to any loading condition. Only the mass proportional damping factor need be adjusted to account for the increased mass of the truss due to a large number of components and obtain actual damped response. The truss in this study is modeled using $1 \mathrm{D}$ beam elements in space with concentrated masses at the joints. Each 
Table 4.9: First five frequencies corresponding to the truss bending and torsion modes.

\begin{tabular}{|c|c|c|}
\hline Mode & Bending Mode $(\mathrm{Hz})$ & Torsion Mode $(\mathrm{Hz})$ \\
\hline 1 & 1.6 & 2.58 \\
2 & 5.16 & 7.79 \\
3 & 9.65 & 13.18 \\
4 & 14.25 & 18.81 \\
5 & 19.37 & 24.76 \\
\hline
\end{tabular}

member of the truss has the same dimensions and material as per the 1D beam with reduced tip mass earlier modeled that gave close frequency and dynamic results with the experimental values. The ten bay truss is in a clamped-free configuration with no diagonals but only battens and longerons. The joints are modeled as lumped masses with values in exact congruence with the estimated mass values of the metallic end caps. Truss models are first prepared in PATRAN ${ }^{\circledR}$ and then the input files are transported to ABAQUS ${ }^{\circledR}$ for analysis. Appendix E contains the input file used to generate the results in Table 4.9. Natural frequencies and corresponding mode shapes for the truss are found along with critical buckling load prediction and buckling modes. The importance of the knowledge of mode shapes, as mentioned earlier lies in the placement of actuators which act as dampers when synchronously activated. These parameters will attain more significance for complex truss shapes. 


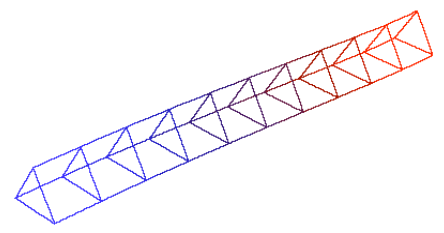

First Bending Mode

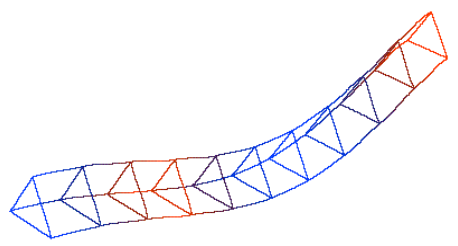

Second Bending Mode

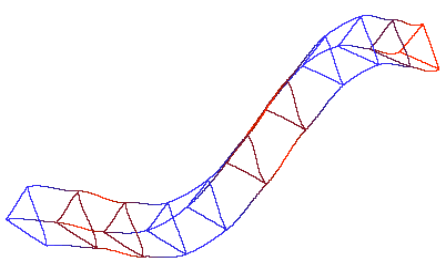

Third Bending Mode

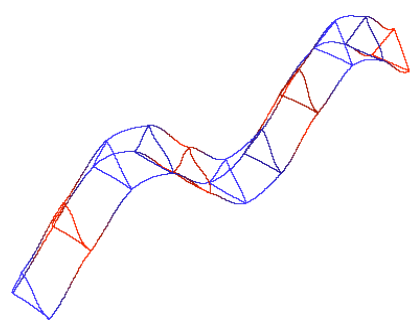

Fourth Bending Mode

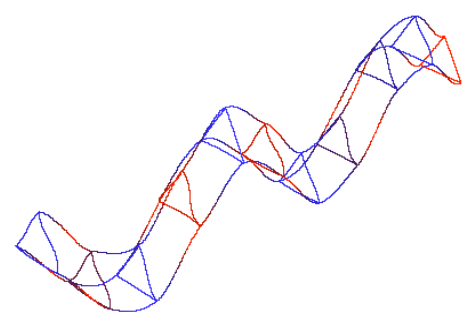

Fifth Bending Mode

Figure 4.16: Truss bending Modes. 


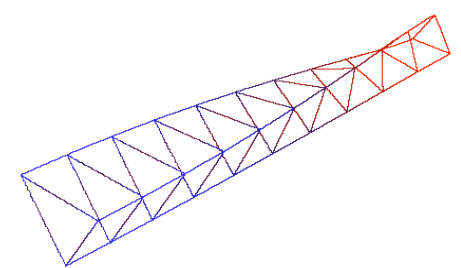

First Torsion Mode

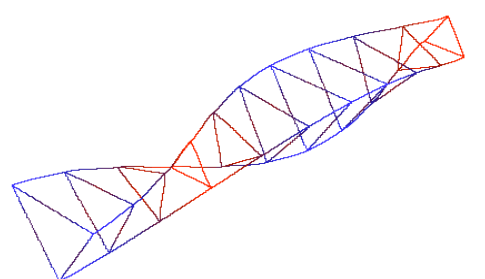

Second Torsion Mode

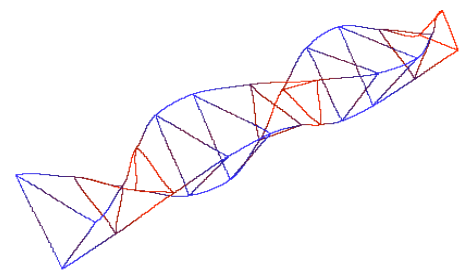

Third Torsion Mode

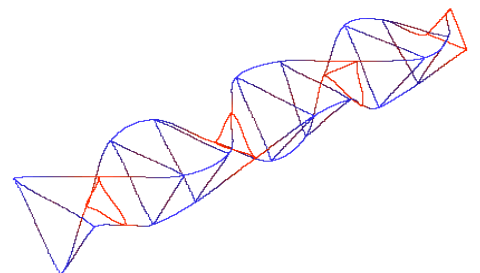

Fourth Torsion Mode

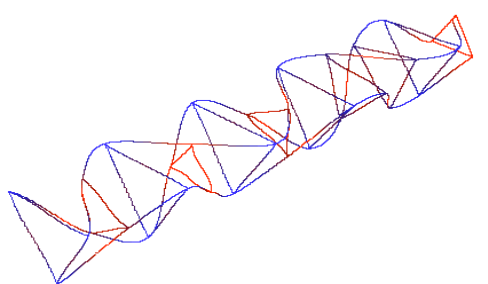

Fifth Torsion Mode

Figure 4.17: Truss torsion modes. 


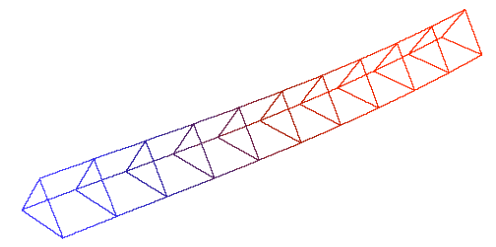

First Buckling Mode

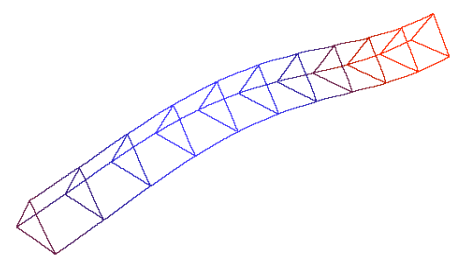

Second Buckling Mode

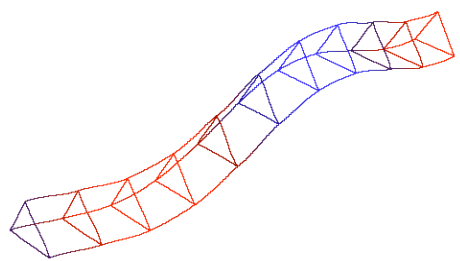

Third Buckling Mode

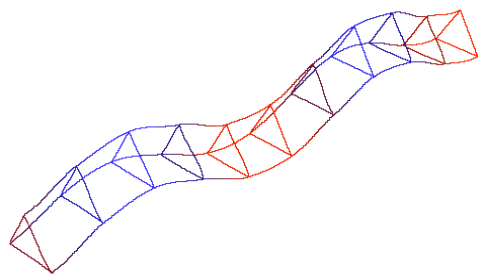

Fourth Buckling Mode

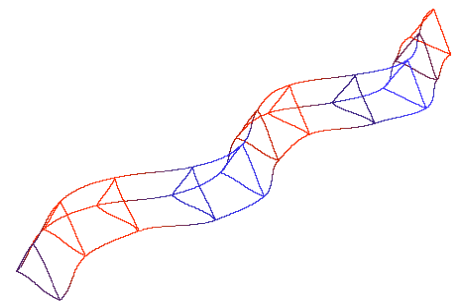

Fifth Buckling Mode

Figure 4.18: Truss buckling modes. 
Table 4.10: Buckling load values.

\begin{tabular}{|c|c|}
\hline Mode & Buckling Load $(\mathrm{N})$ \\
\hline 1 & 8757 \\
2 & 14619 \\
3 & 16761 \\
4 & 19077 \\
5 & 21849 \\
\hline
\end{tabular}

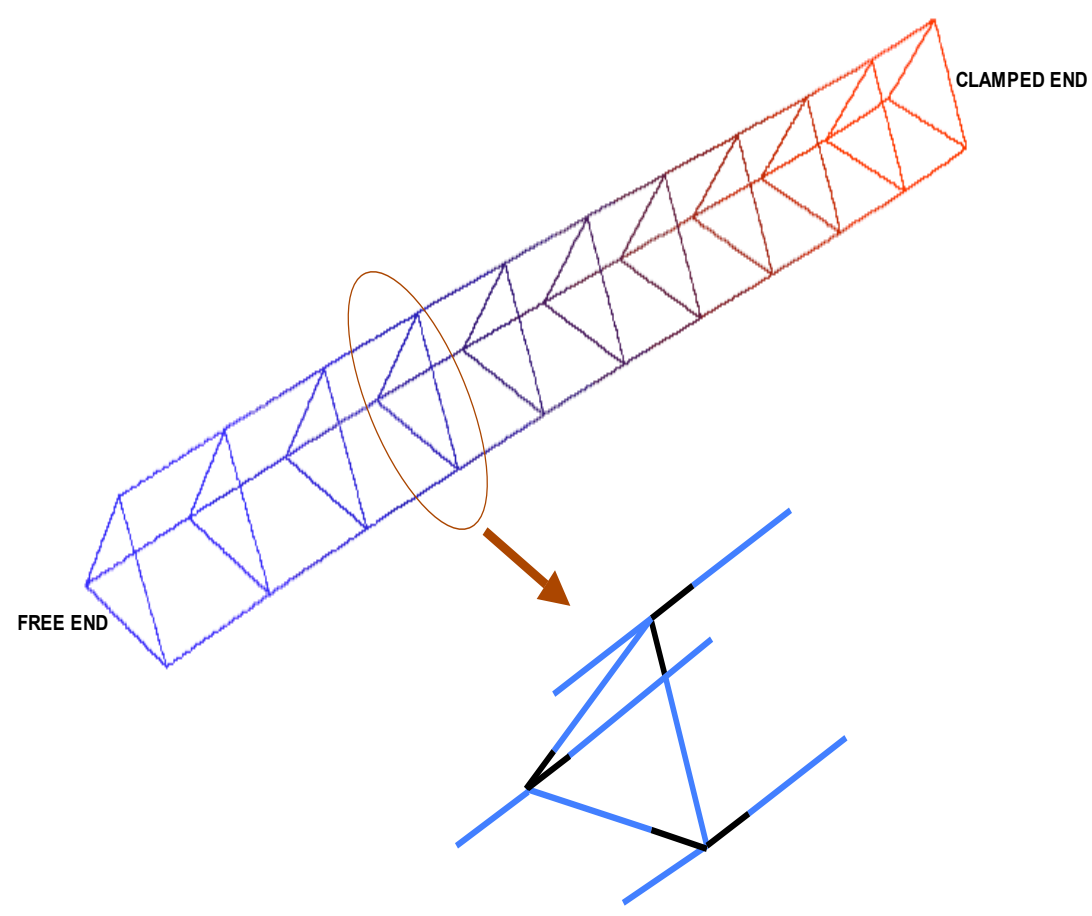

Figure 4.19: Ten bay truss composed of 1D beam elements in a clamped-free configuration. Tube end cap mass is modeled as lumped mass by loading the last element of each of the $1 \mathrm{D}$ beams in the truss with the estimated value of end cap mass. 


\section{Chapter 5}

\section{Conclusion and Future Work}

A composite tube in the form of a boom with end caps is modeled in ABAQUS ${ }^{\circledR}$ for studying its impulse response, natural frequencies and buckling. Experimentally obtained dynamic results were replicated in the modeling and the study was extended to generate more results for cases not studied experimentally. The frequency of the actual structure was selected to be the basis for comparison and results were found to be in close agreement to analytical and experimental results. Since the experimentally measured damping in the form of Rayleigh parameters was not able to produce the desired damping consequently some approximations in the form of artificial damping were used. Approximations were also made in the modeling of the fiber structure as laminas.

The boom being investigated in this study will form a member of a 3D truss to be used in space structure construction purposes. The present work can be extended to a truss with 


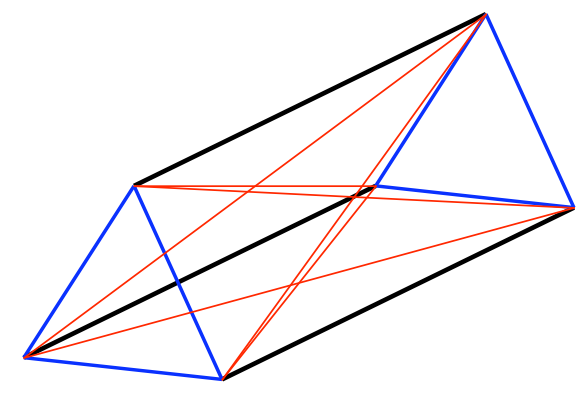

Figure 5.1: A typical repeating element of a truss depicting diagonals, battens and longerons.

tubular members and analyzing its statics and dynamics numerically. As mentioned earlier in this thesis, the distributed loading in the form of internal pressure as well as multitude of dissimilar loadings acting simultaneously on the structure can be easily accomplished in a simulation. The next phase of the study can be modeling the truss with tubular structures and checking the dynamic response to arbitrary loadings. However such an analysis for a ten bay truss with large number of elements will be computationally expensive. Consequently an alternate method for analysis of such repetitive lattice structures known as Continuum Modeling can be used which is based on developing equivalent beam models which have same amount of strain and kinetic energy stored when both are deformed identically. The utility of this method lies in comparing the structural characteristics of lattices with different configurations and assessing the sensitivity of their responses to variations in material and geometric properties. This mode of analysis is very useful from a preliminary 
design point of view [29]. However, more validation of the numerical responses with the different set of experimental outputs could be done to arrive at a universal model capable of giving accurate results for any set of loading conditions. Modeling the tube to MFC actuation can be the first step in that direction. Furthermore, the tube can be pressurized and the response of the tube to similar impulse inputs can be investigated and a numerical match with the current model can be attempted. Not only the loading conditions but the current boundary conditions can be changed for generating more experimental results, such as a tube with both end caps clamped. Specimens with the same material but different dimensions can also be built and tested followed by a similar numerical investigation. Once the numerical tube model gives a perfect match with different set of experimental outputs the numerical model can be used for generating results not possible in the laboratory environment. 


\section{Bibliography}

[1] Bush, H.G., Mikulas, M., and Heard, W., "Some Design Considerations for Large Space Structures," AIAA Journal, Vol. 16, No. 4, 1978, pp. 352-359.

[2] Padula, S., Sandridge, C., Walsh, J., and Haftka, R.T., "Integrated Controls Structures Optimization of Large Space Structures," Computers and Structures, Vol. 42, No. 5, 1992, pp. 725-732.

[3] Lazan, B.J., Damping of Materials and Members in Structural Mechanics, Pergamon, Elmsford, NY, 1968, pp. 35, 36.

[4] Beards, C.F., "Damping on Structural Joints," Shock and Vibration Digest, Vol. 11, No. 9, 1979, pp. 35-41.

[5] Chen, G.S. and Wada, B.K., "Passive Damping for Space Structures," Structural Dynamics and Materials Conference, 29th, Williamsburg, VA, Technical Papers, Part 3, 1988, pp. 1742-1749.

[6] Malla, R.B., Adib-Jahromi, H.R. and Accorsi, M.L., "Passive Vibration Suppression 
in Truss-Type Structures with Tubular Members," Journal of Spacecraft and Rockets, Vol. 37, No. 1, 2000, pp. 86-92.

[7] Zabaras, N. and Pervez, T., "Viscous damping approximation of laminated anisotropic composite plates using the finite element method," Computer Methods in Applied Mechanics and Engineering, Vol. 81, No. 3, August 1990, pp. 291-316.

[8] Chandra, R., Singh, S.P. and Gupta, K., "Damping Studies in Fiber-Reinforced Composites - a Review," Composite Structures, Vol. 46, No. 1, September 1999, pp. 41-51.

[9] Nashif, A.D., Jones, D.I.G. and Henderson, J.P., Vibration Damping, John-Wiley and Sons, New York, 1985.

[10] Sattinger, S.S., "Constrained Layer Damping Effectiveness on Members Under Vibratory Extensional Loading," Westinghouse Research and Development Center, Pittsburgh, Pennsylvania, November 1984.

[11] Hedgepeth, J.M. and Mobrem, M., "Investigation of Passive Damping of Large Space Truss Structures," Damping 1986 Proceedings, 1986.

[12] Rao, M.D., Echempati, R. and Nadella, S., "Dynamic Analysis and Damping of Composite Structures Embedded with Viscoelastic Layers," Composites Part B: Engineering, Vol. 28, No. 5-6, 1997, pp. 547-554.

[13] www.ilcdover.com 
[14] Hagood, N.W. and Crawley, E.F., "Experimental Investigation into Passive Damping Enhancement for Space Structures," Journal of Guidance Control and Dynamics, Vol. 14, No. 6, 1991, pp. 1100-1109.

[15] Hagood, N.W. and Crawley, E.F., "A Frequency Domain Analysis for Damped Space Structures," AIAA, ASME, ASCE, AHS, and ASC, Structures, 30th Structural Dynamics and Materials Conference, Mobile, AL, UNITED STATES, 1989, pp. 19361946.

[16] Sankar, B.V. and Deshpande, A.S., "Passive Damping of Large Space Structures," AIAA Journal, Vol. 31, No. 8, 1993, pp. 1511-1516.

[17] Simonian, S., Lukich, M.S. and Gluck, R., "On a Balanced Passive Damping and Active Vibration Supression of Large Space Structures," AIAA-1987-901 Dynamics Specialists Conference, Monterey, CA, Apr 9-10 1987.

[18] Trudell, R.W., Curley, R.C. and Rogers, L.C., "Passive Damping in Large Precision Space Structures," AIAA-1980-677 Structures, Structural Dynamics, and Materials Conference, 21st, Seattle, Wash., May 12-14, 1980, Technical Papers. Part 1. (A8034993 14-39) New York, American Institute of Aeronautics and Astronautics, Inc., 1980, pp. 124-136.

[19] Rittweger, A., Albus, J., Hornung, E. and Mourey, P., "Passive Damping Devices for Aerospace Structures," Acta Aeronautica, Vol. 50, No. 10, pp. 597-608, May 2002. 
[20] Pamley, R.J., House, J.R. and Brennan, M.J., "Comparison of Passive Damping Treatments for Hollow Structures," Smart Structures and Materials 2001, Damping and Isolation, Proceedings of the Conference, Newport Beach, CA, 5-7 March 2001 pp. $455-467$.

[21] Alsweify, Khaled A., Kolkailah, Faysal A., Booker, Cecilia, Elghandour, Eltahry I. and Farghaly, Said H., "Dynamic Response of Carbon/Epoxy Cantilever plates with Passive Damping," Materials and Process Affordability - Keys to the Future, Proceedings of the 43rd International SAMPE Symposium and Exhibition, Anaheim, CA, 31 May-4 June 1998. pp. 426-430.

[22] Johnson, C., "Passive Damping Technology using Viscoelastics," IEEE Conference on Decision and Control, 30th, Brighton, United Kingdom, 11-13 Dec. 1991 pp. 25462551.

[23] Edberg, D. and Bicos, A., "Design and Development of Passive Damping Concepts in Advanced Composite Large Space Structures," International SAMPE Symposium and Exhibition, 36th, San Diego, CA, 15-18 Apr 1991 pp. 1-12.

[24] Williams, R.B., "Nonlinear Mechanical and Actuation Characterization of Piezoceramic Fiber Composites," Ph.D. Thesis, Department of Mechanical Engineering, Virginia Polytechnic Institute and State University, Blacksburg, Virginia, 2004. 
[25] Hibbitt, Karlson and Sorensen, Inc.. ABAQUS/Standard Theory Manual: Version 5.8, Pawtucket, RI, 1998.

[26] www.kapton.com

[27] Muki, R. and Sternberg, E., "On Transient Thermal Stresses in Viscoelastic Materials with Temperature-Dependent Properties," Journal of Applied Mechanics, Vol. 28, No. 2, 1961, pp. 193-207.

[28] Timoshenko, S.P., Theory Of Elastic Stability, McGraw-Hill Book Company, 1961, pp. $457-519$.

[29] Noor, A.K., "Continuum Modeling for Repetitive Lattice Structures," Applied Mechanics Review, Vol. 41, No. 7, July 1998 pp. 285-295.

[30] Flügge,W., Viscoelasticity, 2nd. Ed., Springer-Verlag, New-York, 1975.

[31] Christensen, R.M., Theory of Viscoelasticity, An Introduction, 2nd ed., Academic Press, New York 1982.

[32] Haddad, Y.M., Viscoelasticity of Engineering Materials, Chapman and Hall, UK, 1995. 


\section{Appendix A}

\section{Half Power Method}

Every mode has a different damping factor associated with it. To determine the damping factor from the Frequency Response Function plots the Half Power Method is employed. The following steps are sequentially followed.

- Select the resonant peak in the FRF corresponding to which the damping factor is desired.

- The magnitude of the amplitude of the resonant peak is determined.

- Magnitudes of the Half Power points around the peak are found. Half Power points correspond to the response amplitudes where its value is 0.707 times the peak amplitude.

- The frequencies corresponding to the half power points which are two in number on 
either side of the main peak are found.

- If the frequencies corresponding to the Half Power point amplitudes are given by $\Omega_{1}$ and $\Omega_{2}$, then the damping factor is given by

$$
\zeta=\frac{\Omega_{2}-\Omega_{1}}{2 \omega_{n}}
$$

where $\omega_{n}$ is the natural frequency corresponding to the peak.

- The accuracy of the procedure lies in the resolution of the original Frequency Response Function plot

The values of the $\zeta$ obtained for different peaks can be used to find the values of the Rayleigh Damping Parameters $\alpha$ and $\beta$ from the following expression to be solved for natural frequencies corresponding to the bending modes of the specimen. It is thus required to do a continuum $1 \mathrm{D}$ beam model study of structures so as to determine which modes correspond to the beam bending modes.

$$
\zeta_{i}=\frac{\alpha+\beta\left(\omega_{i}\right)^{2}}{2 \omega_{i}}
$$

where $\omega_{i}$ corresponds to the natural frequency corresponding to the $i^{\text {th }}$ bending mode. 


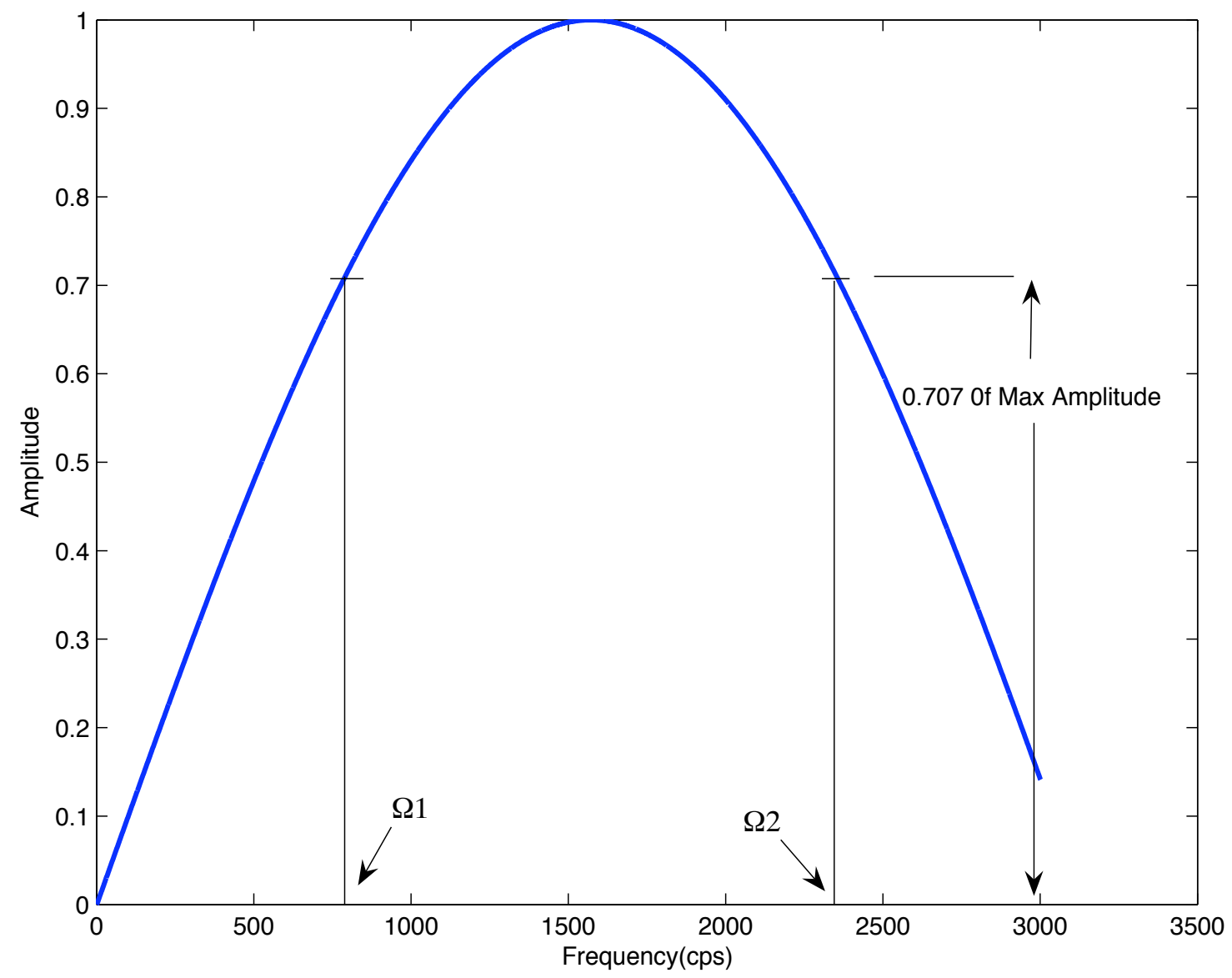

Figure A.1: Frequency response curve depicting Half Power Points and corresponding frequencies for a peak corresponding to the beam bending mode. 


\section{Appendix B}

\section{Linear Viscoelasticity}

\section{B.1 Introduction}

This appendix is a brief introduction to the basics of linear viscoelasticity. For more in-

depth study the reader must refer to texts by Flugge [30], Christensen [31] and Haddad [32]. This appendix follows the text by Haddad [32].

A linear elastic solid is a material which obeys the Hooke's law of linear proportionality of stress to strain through Young's modulus. The mechanical analog of such a behavior is a linear spring which can store energy which is available to do work.

$$
\sigma=E \epsilon
$$


A linear viscous fluid is one in which the strain rate is proportional to the stress and the constitutive law is

$$
\sigma=\eta \dot{\epsilon}
$$

The mechanical analog of such a behavior is a Newtonian dashpot which does not store any energy and all work done on the element is dissipated.

Viscoelasticity is the study of materials which exhibit a combination of both elastic and viscoelastic behavior. The linear viscoelastic behavior of materials can be mechanically modeled as a combination of springs and dashpots. The strain response behavior of such materials under a stress loading of unit magnitude and their comparison with other types of materials under similar loading conditions is depicted in Figure B.1. Viscoelastic materials are usually studied from two phenomenological aspects

- Creep response under constant stress in which an arbitrary stress input results in a time dependent strain response.

- Stress Relaxation response under constant strain in which an arbitrary strain input results in a time dependent stress response. 


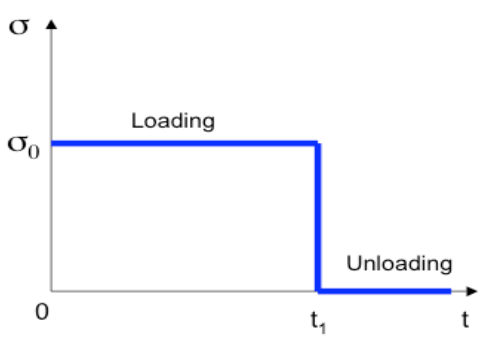

Stress Function

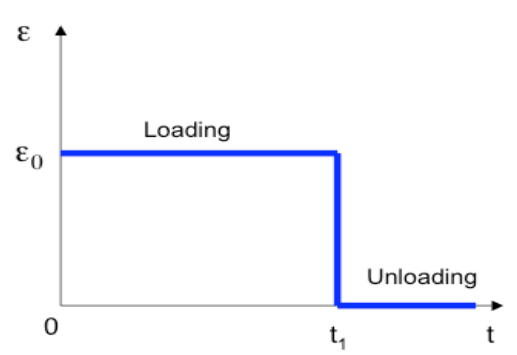

Strain Response for Elastic Material

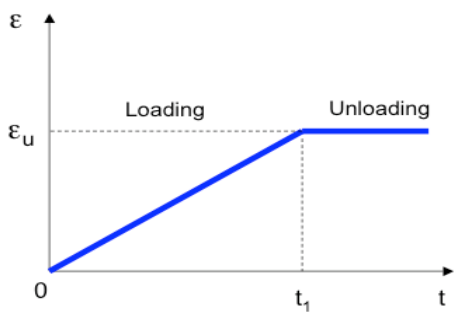

Strain Response for Viscous Fluid

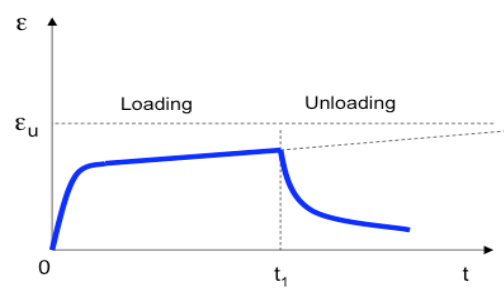

Strain Response for Viscoelastic Material

Figure B.1: Strain response of Elastic, Viscous and Viscoelastic materials to identical stress loading. 

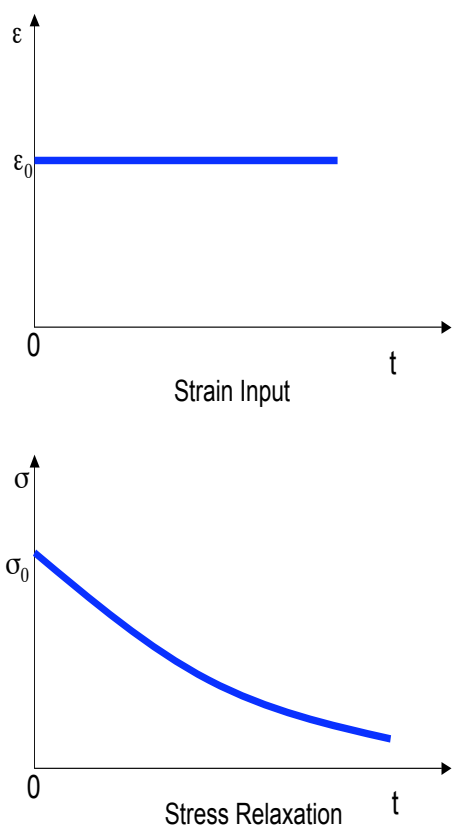

Figure B.2: Stress relaxation of viscoelastic material subjected to a constant strain. 


\section{B.2 Constitutive Equations}

Linear Viscoelastic materials have the following linear differential equation relating the stress to the strain.

$$
P \sigma(t)=Q \epsilon(t)
$$

where

$$
\begin{aligned}
& P=\sum_{i=0}^{p} a_{i} \frac{\partial^{i}}{\partial t^{i}} \\
& Q=\sum_{i=0}^{q} b_{i} \frac{\partial^{i}}{\partial t^{i}}
\end{aligned}
$$

or as

$$
a_{0} \sigma+a_{1} \frac{d \sigma}{d t}+a_{2} \frac{d^{2} \sigma}{d t^{2}}+\cdots=b_{0} \epsilon+b_{1} \frac{d \epsilon}{d t}+b_{2} \frac{d^{2} \epsilon}{d t^{2}}+\cdots
$$

where $a_{i}$ and $b_{i}$ are material constants.

\section{B.3 Mechanical Models}

There are various mechanical models for studying the viscoelastic behavior of materials

- Kelvin (Voigt) Model: This model consists of a Hookean Spring and a dashpot combined in parallel. The parallel combination constrains the basic elements to deform by the same amount and the total stress equalling the sum of stresses in the 
spring and dashpot. The governing differential equation becomes

$$
\sigma=E \epsilon+\eta \dot{\epsilon}
$$

- Maxwell model: This model consists of a Hookean Spring and a dashpot connected in series. When subjected to opposing stresses the total strain developed in the model is the sum of the individual strains in the spring and dashpot. The governing differential equation in this case is

$$
\sigma+\frac{\eta}{E} \dot{\sigma}=\eta \dot{\epsilon}
$$

- Three Parameter Solid: This mechanical analog consists of a Voigt model and a linear spring in series. The differential equation being

$$
\sigma+\frac{\eta}{E+E^{\prime}} \dot{\sigma}=\frac{E E^{\prime}}{E+E^{\prime}} \epsilon+\frac{E \eta}{E+E^{\prime}} \dot{\epsilon}
$$

Furthermore, generalized models can be created by a combination of the above three basic types of models. Two models are of particular interest. These are

- The generalized Maxwell model: Basic Maxwell units are connected in parallel

- The generalized Kelvin (Voigt) model: A number of Kelvin models are connected in series. 


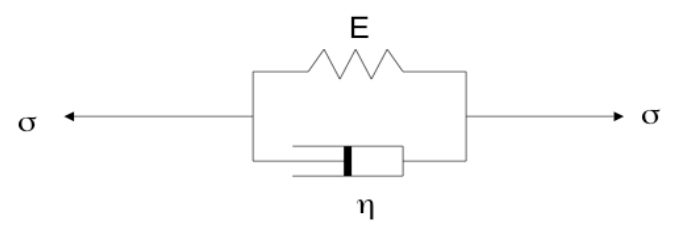

(a)

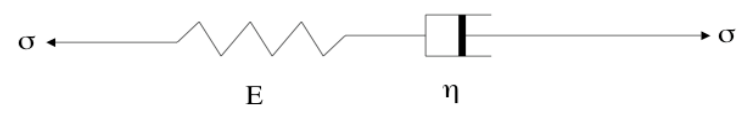

(b)

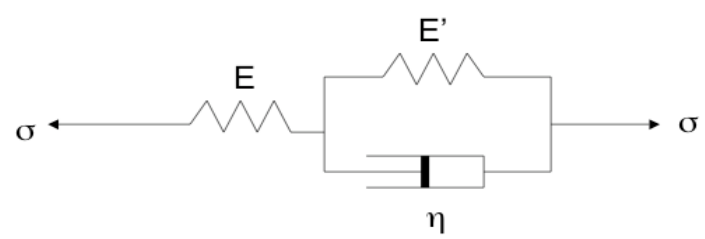

(c)

Figure B.3: Mechanical model analogues: a. Kelvin(Voigt) Model b. Maxwell Model c. Three Parameter Solid. 


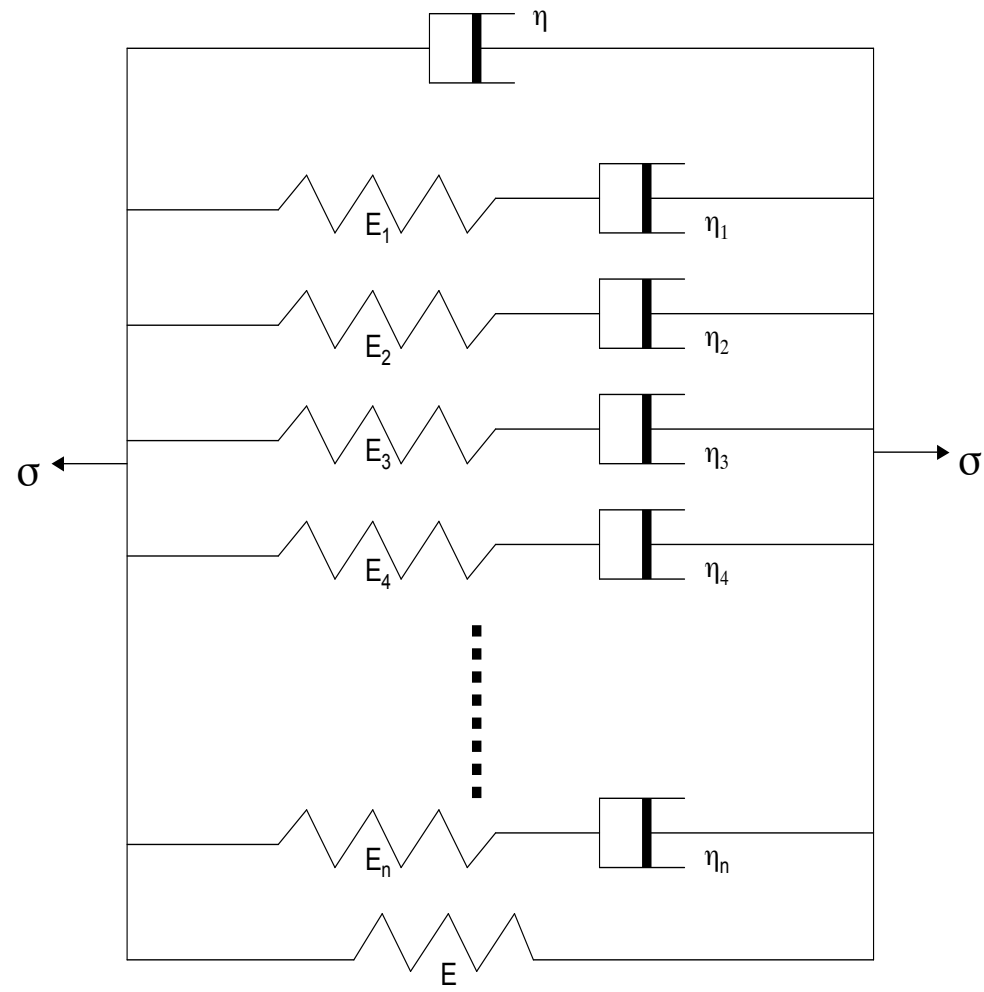

Figure B.4: Generalized Maxwell model. 


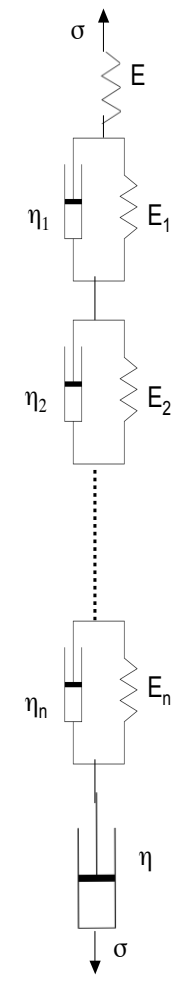

Figure B.5: Generalized Kelvin (Voigt) model. 


\section{Appendix C}

\section{End Cap Dimensions}

The tube being modeled in the present study has end caps made of aluminum at both its ends glued tightly to the tube material. The dimensions of the end caps were obtained from the manufacturers (ILC Dover).

Table C.1: Computed volume and mass for the end cap.

\begin{tabular}{|c|c|}
\hline Physical Parameters & Value \\
\hline Volume $\left(\mathrm{m}^{3}\right)$ & $7.68 \times 10^{-5}$ \\
Mass $(\mathrm{Kg})$. & 0.207 \\
Density $\left(\mathrm{Kg} \cdot / \mathrm{m}^{3}\right)$ & 2700 \\
\hline
\end{tabular}




\section{NASA-ILC INFLATABLE STRUT END-CAP \\ (Dimensions in inches)}

Material: Al, any grade

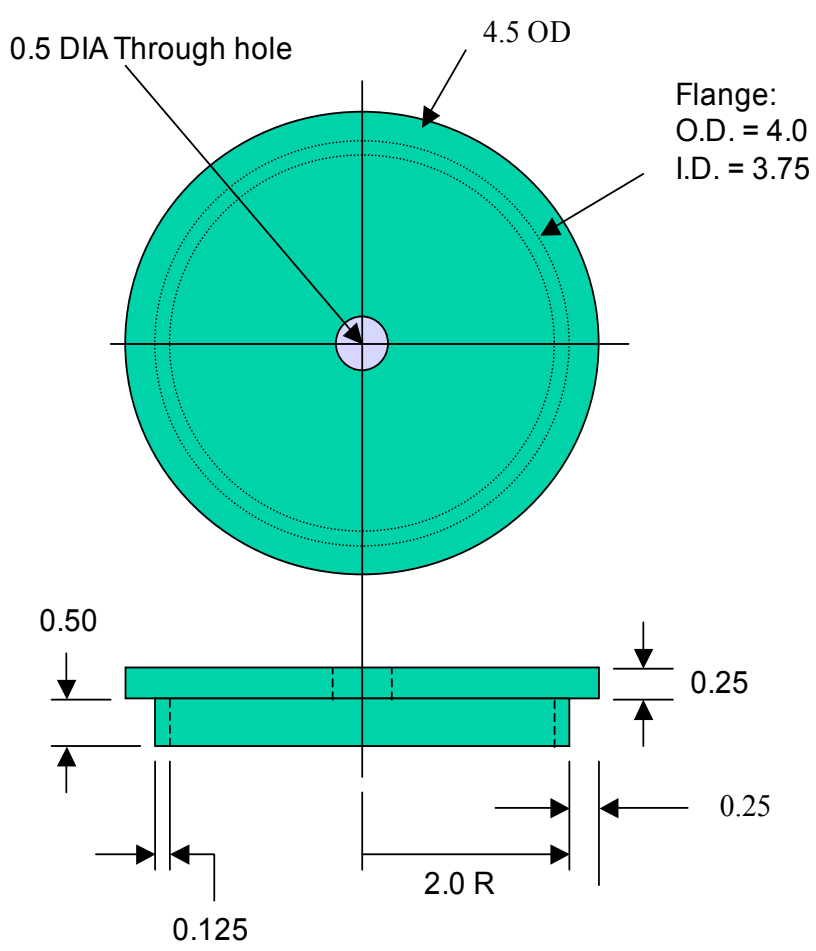

Figure C.1: Tube End Cap Dimensions. 


\section{Appendix D}

\section{ABAQUS ${ }^{\circledR}$ Input File}

One of the input file that was used to simulate the tube dynamics is appended below. The node connectivities, element definitions and node numbering has been truncated to conserve space. The file lists the ABAQUS ${ }^{\circledR}$ commands used in the preparation of the input file for a composite-viscoelastic tube with end caps. The properties of the orthotropic Carbon fibers were reduced and the estimated mass of the end cap was used. Approximations in the form of layered composites as well as Rayleigh damping parameter $\alpha$ have been incorporated.

*NODE

$1,0.0508,0$.

$2,0.0483154,0.0156928$

3, 0.0411034, 0.0298522

4, 0.0298705, 0.0410901

$*$ ELEMENT, TYPE=S4R5, ELSET $=$ SHELL 
$1,1,2,23,22$

$2,2,3,24,23$

$3,3,4,25,24$

$4,4,5,26,25$

*ELEMENT, TYPE=C3D4, ELSET=SOLID

$1201,1282,1288,1408,1283$

$1202,1414,1408,1288,1415$

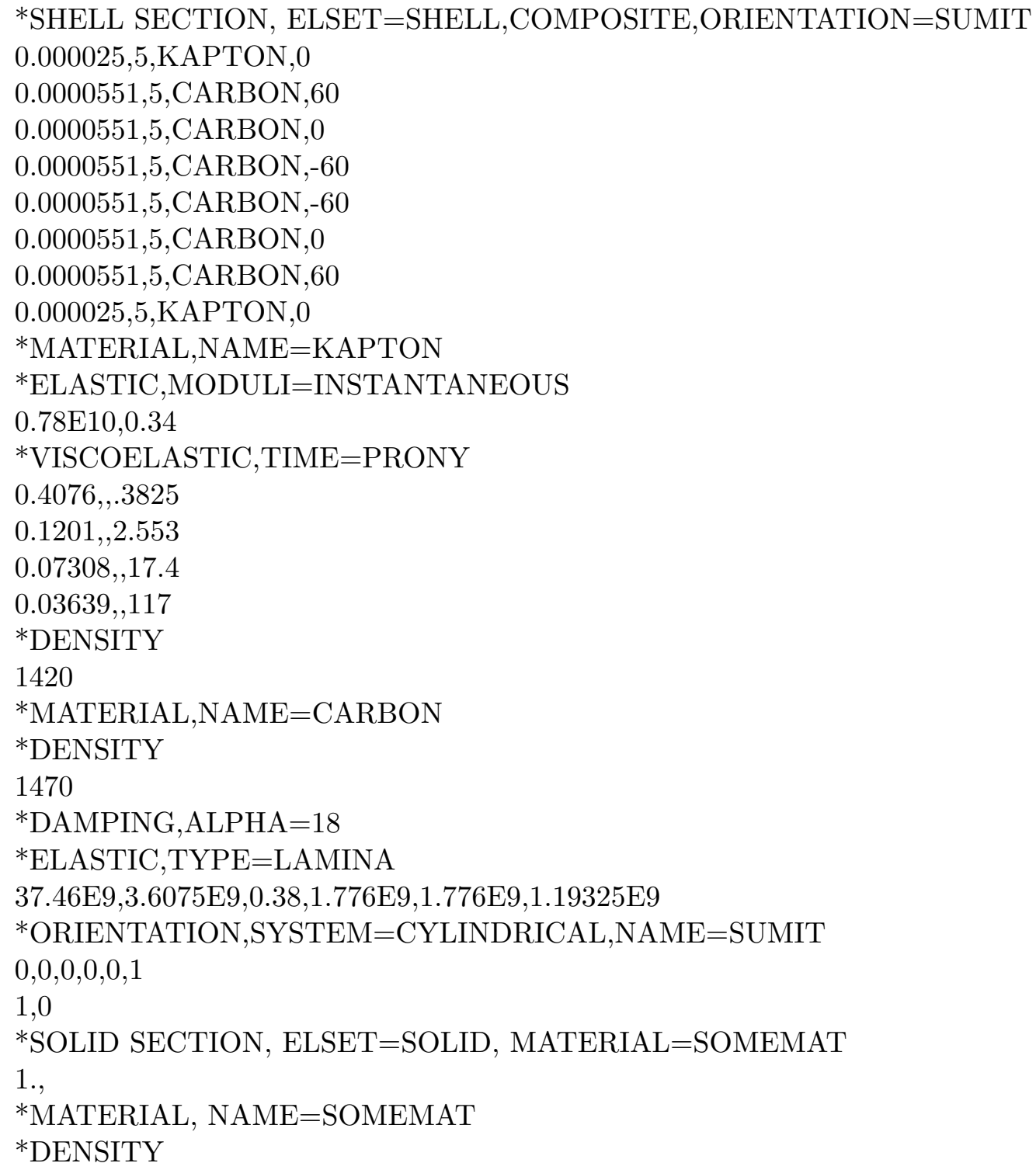


1878.26

*ELASTIC

$7 \mathrm{E}+10,0.34$

*BOUNDARY

CLAMPED, $1,0$.

CLAMPED, $2,0$.

CLAMPED, 3, 0 .

*BOUNDARY

CLAMPED, $4,0$.

CLAMPED, 5,0 .

CLAMPED, $6,0$.

*NSET, NSET=CLAMPED, GENERATE

$1,20,1$

*NSET, NSET $=$ FORCE

1539 ,

*STEP, INC $=15000000000$

*DYNAMIC

$0.0001,0.8$

*AMPLITUDE,NAME $=$ CURVE,DEFINITION $=$ TABULAR

$0.0008,-0.5874,0.0016,-0.6114,0.0023,-0.6834,0.0031,-0.4316$

$0.0039,-0.9711,0.0047,-0.0360,0.0055,-1.4506,0.0063,0.5155$

$0.0070,-2.0141,0.0078,0.8992,0.0086,-1.9062,0.0094,-0.3117$

$0.0102,64.4152,0.0109,6.5698,0.0117,-5.1072,0.0125,2.4577$

$0.0133,-3.1171,0.0141,0.9591,0.0148,-1.9062,0.0156,-0.0480$

$0.0164,-1.1629,0.0172,-0.5635,0.0180,-0.8392,0.0188,-0.7553$

${ }^{*}$ CLOAD, AMPLITUDE $=$ CURVE

FORCE, 1, 1.

*END STEP 


\section{Appendix E}

\section{ABAQUS ${ }^{\circledR}$ Input File For Truss}

The input file prepared for generating the results of Table 4.9 is appended below. The node connectivities, element definitions and node numbering has been truncated to conserve space. The file lists the ABAQUS ${ }^{\circledR}$ commands used in the preparation of the input file for a ten bay truss composed of 1D Beam elements with tip masses. Each member of the truss has the same dimensions and material as per the 1D beam with reduced tip mass earlier modeled that gave close frequency and dynamic results with the experimental values.

*NODE

$1,0 ., 0$.

$2,0.61275,1.06131$

$3,0.61275,1.06131,1.2255$

$4,0.61275,1.06131,2.451$

$5,0.61275,1.06131,3.6765$

$*$ ELEMENT, TYPE=B31 , ELSET=BEAM

$34,1,35$

$35,35,36$ 
$36,36,37$

$37,37,38$

$38,38,39$

$39,39,40$

$40,40,41$

*BEAM SECTION, ELSET=BEAM, SECTION=PIPE, MATERIAL=SOMEMAT 0.0508, 0.000381,

1., 1., 0.

$*$ MASS,ELSET $=$ M1

0.145

$*$ MASS,ELSET $=\mathrm{M} 2$

0.290

*MATERIAL, NAME=SOMEMAT

*DENSITY

1470 ,

*ELASTIC

$1.35 \mathrm{E}+10,0.34$

*BOUNDARY

DISPLACE, $1,0$.

DISPLACE, 2, 0.

DISPLACE, 3,0 .

*BOUNDARY

DISPLACE, $4,0$.

DISPLACE, $5,, 0$.

DISPLACE, $6,0$.

*NSET, NSET=DISPLACE

$1,2,23$

*STEP

*FREQUENCY

100

*END STEP 


\title{
Appendix F
}

\section{Nomenclature}

\author{
$[\mathrm{A}]=$ Extension Stiffness \\ $[\mathrm{B}]=$ Bending-Extensional Coupling \\ $[\mathrm{D}]=$ Bending Stiffness \\ $[\mathrm{M}]=$ Mass Matrix \\ $[\mathrm{K}]=$ Stiffness Matrix \\ $E_{0}=$ Instantaneous Modulus \\ $p_{i}=i^{t h}$ Prony Constant \\ $\tau_{i}=i^{\text {th }}$ Prony Retardation Time Constant \\ $\mathrm{E}(\mathrm{t})=$ Relaxation Modulus at some time $\mathrm{t}$ \\ $\mathrm{Y}(\mathrm{x})=$ Transverse Displacement \\ $\mathrm{I}=$ Area Moment of Inertia of Beam Cross Section
}


$\omega=$ Circular Frequency of Vibration of Beam

$\beta=$ Eigenvalue Appearing in Beam Vibration Problem

$\mathrm{m}=$ mass per unit length of the beam

$\mathrm{L}=$ length of the beam

$\mathrm{M}=$ Concentrated Mass attached at the Beam Tip

$\mathrm{G}=$ Shear Modulus of Elasticity of Shaft Material

$\nu=$ Poisson's Ratio for Shaft Material

$\theta(x)=$ Modal Shape of Torsional Vibration as a Function of $\mathrm{x}$

$\rho=$ Density of the Shaft Material

$I_{p}=$ Polar Moment of Inertia of Shaft Cross Section

$I_{0}=$ Moment of Inertia of Rotational Mass attached to Shaft

$P_{c r}=$ Critical Buckling Load

$\mathrm{h}=$ Thickness of the Tube

$\mathrm{a}=$ Radius of the Tube

$\sigma_{c r}=$ Critical Buckling Stress

$\zeta=$ Damping Factor

$\Omega_{1}, \Omega_{2}=$ Frequencies Corresponding to Half Power Point Amplitudes.

$\alpha=$ Rayleigh Damping Factor for Mass Proportional Damping

$\beta=$ Rayleigh Damping Factor for Stiffness Proportional Damping

$\mathrm{t}=$ time

All Units follow SI Convention 